\title{
Extensive assessment of the charge-trapping kinetics in InGaAs MOS gate-stacks for the demonstration of improved BTI reliability
}

\author{
Vamsi Putcha ${ }^{1, \dagger}$, Jacopo Franco ${ }^{1}$, Abhitosh Vais ${ }^{1}$, Ben Kaczer ${ }^{1}$, Qi Xie ${ }^{3}$, Jan Willem Maes ${ }^{4}$, Fu Tang ${ }^{4}$, Michael \\ Givens $^{4}$, Nadine Collaert ${ }^{1}$, Dimitri Linten ${ }^{1}$, Guido Groeseneken ${ }^{1,2}$ \\ †vamsi.putcha@imec.be, $\quad{ }^{1}$ IMEC, Belgium, $\quad{ }^{1}$ ESAT, KU Leuven, Belgium, ${ }^{3}$ ASM Belgium, ${ }^{4}$ ASM America, USA
}

\begin{abstract}
Gate-stack reliability has been a major roadblock in the realization of InGaAs-channel based logic technology. Excessive charge trapping in the gate-oxide causes time-dependent drift in transistor threshold voltage $\left(V_{t h}\right)$. The extent to which $V_{t h}$ drifts under certain stress conditions depends on (i) the defect ground-state energy distributions in the oxide bandgap, and (ii) the specific activation energy distributions for charge capture/emission process. In this work, semi-empirical modelling of ground-state defect energy distributions is revisited to determine the Total Operating Voltage Range of InGaAs-based MOSFETs for a DC-BTI lifetime of 10 years under DC operating conditions. Non-radiative Multiphonon (NMP) theory is subsequently used to describe the microscopic physics of charge (de-)trapping kinetics in terms of activation energy barriers for charge capture $\left(E_{A c}\right)$ and emission $\left(E_{A e}\right)$ into/from gate-stack defects. These activation energy barriers are visualized using Capture/Emission Time (CET) maps, which are efficient and powerful tools to predict the BTI degradation under different AC operating conditions as well. We demonstrate that the enhanced BTI reliability of a gate-stack with a novel ASM interfacial layer (ASM-IL) as compared to the bilayer gate-stack of $\mathrm{Al}_{2} \mathrm{O}_{3} / \mathrm{HfO}_{2}$, results from the favorable reconfiguration of the defect energy distribution in the oxide bandgap, as well as their activation energies for capture and emission process.
\end{abstract}

Index Terms-Bias Temperature Instability (BTI), InGaAs, gate-stack reliability, NMP theory, defect-band modelling, Total Operating Voltage Range, Capture/Emission Time (CET) maps, ASM-IL, opposite-Arrhenius-temperature-dependence.

\section{INTRODUCTION}

$\mathrm{T}$ enable future high-speed and low-power logic technologies, MOSFETs with high mobility channel materials are being explored as they provide higher drive current for scaled dimensions [1-4]. InGaAs has a lower bandgap $(0.72 \mathrm{eV})$ than $\mathrm{Si}$, and higher electron mobility, thus making it a suitable candidate for channel material for future low-power MOS devices. Complementary MOS (CMOS) logic technology with SiGe-based pMOS devices and InGaAs-based nMOS devices in a co-integrated Quantum-well field effecttransistor (QW-FET) configuration was demonstrated in [5].

Unlike the favourable $\mathrm{Si} / \mathrm{SiO}_{2}$ interface of contemporary CMOS logic devices, native oxides of InGaAs lack good interface properties [6], which has led to a considerable research interest in interface engineering of InGaAs nMOS devices [7-13]. In addition, achieving good gate-stack reliability of InGaAs-based MOSFETs has been extremely challenging with continuous technology scaling.

The operating lifetime of the device is affected by Bias-
Temperature Instability (BTI), due to charge trapping into defects in the dielectric-stack, which results in shift of the threshold voltage $\left(V_{t h}\right)$ of the device $[3,4]$. It was shown that devices could achieve rather low maximum overdrive voltage (max $-V_{o v}$ ) of $\sim 0.2 \mathrm{~V}$ for DC operating lifetime of 10 years with $\mathrm{Al}_{2} \mathrm{O}_{3}$ as the gate-dielectric [14]. Careful engineering of the defect energy distributions is needed to improve device performance and reliability. However, the determination of the ground state defect energy distributions as discussed in [15] may be inadequate to accurately predict the device lifetime under AC (or high frequency RF) conditions and at cryogenic temperatures, as it requires in-depth modelling of defect characteristics controlling the (dis-)charging kinetics.

A novel ASM interfacial layer (ASM-IL) based gate-stack was shown to provide excellent interface properties, while also improving the operating lifetime of the device, using the defectband modelling methodology [15]. This work (i) reviews the modelling of ground-state defect energy distributions in the bandgap of high-k based gate-stacks; (ii) provides the physical insight behind the improved reliability performance of the gatestack comprising $1 \mathrm{~nm}$ ASM-IL/1nm $\mathrm{LaSiO}_{x} / 3 \mathrm{~nm} \mathrm{HfO}_{2}$ using the CET map methodology, in accordance with the atomistic defect model based on the Non-radiative Multiphonon (NMP) theory [16]; (iii) provides a direct comparison of the trapping/de-trapping kinetics of the defects in the gate-stack of the ASM-IL using the calibrated CET map, with the CET map previously calibrated on the $\mathrm{Al}_{2} \mathrm{O}_{3}$ gate-stack; and (iv) validates the AC-BTI results for the $\mathrm{Al}_{2} \mathrm{O}_{3}$ gate-stack.

Section II provides an overview of the processing conditions and schematic illustration of the structure of InGaAs MOSFETs used in this study, along with the experimental details. Section III revises the methodology for modelling of the defect energy distributions in the oxide bandgap, demonstrating the improvements in reliability due to the inclusion of the ASM-IL. Section IV illustrates how Capture/Emission Time (CET) maps can be used to understand the kinetics of charge trapping. Section V summarizes the experimental results and discusses the CET maps modelled for the ASM-IL based gate-stack. Section VI is dedicated to the detailed comparison of the gatestack reliability between the bi-layer $\left(\mathrm{Al}_{2} \mathrm{O}_{3} / \mathrm{HfO}_{2}\right)$ and the ASM-IL based gate-stacks. The two gate-stacks are benchmarked against the advanced Si MOS devices in Section VII. Finally, Section VIII summarizes the main conclusions regarding reliability of gate-stacks for InGaAs channel MOSFETs. 


\section{EXPERIMENTAL DETAILS}

BTI reliability of the gate-stack was studied in MOScapacitors (MOSCAPs) and Implant-free quantum-well (IFQW) MOSFETs [5]. The structures of the MOSCAP and MOSFET are schematically illustrated in Fig.1. All samples were fabricated as described in [3, 17]. MOSCAPs were fabricated by growing $300 \mathrm{~nm}$ of $\mathrm{n}-\mathrm{In}_{0.53} \mathrm{Ga}_{0.47} \mathrm{As}$ (Si-doped, $N_{D}=5 \times 10^{16} \mathrm{~cm}^{3}$ ) using MBE on a 2" n-InP substrate. The MOSFET consists of a $15 \mathrm{~nm}$ un-intentionally doped $\mathrm{In}_{0.53} \mathrm{Ga}_{0.47} \mathrm{As}$ channel layer, a $3 \mathrm{~nm}$ InP etch stop layer and a 50 $\mathrm{nm} n+\mathrm{In}_{0.53} \mathrm{Ga}_{0.47} \mathrm{As}$ (Si-doped, $1 \times 10^{19} \mathrm{~cm}^{-3}$ ) layer, all grown on a 2-inch semi-insulating InP substrate [15].

Two different gate-stacks are studied in this work, namely, InGaAs $/ 1 \mathrm{~nm} \mathrm{Al}_{2} \mathrm{O}_{3} / 3 \mathrm{~nm} \quad \mathrm{HfO}_{2} / \mathrm{TiN}$ gate (henceforth called " $\mathrm{Al}_{2} \mathrm{O}_{3}$ " gate stack), and InGaAs/ $1 \mathrm{~nm}$ ASM-IL/ $1 \mathrm{~nm}$ $\mathrm{La}_{58} \mathrm{SiO}_{\mathrm{x}} / 3 \mathrm{~nm} \mathrm{HfO}_{2} / \mathrm{TiN}$ gate (henceforth called "ASM-IL" gate stack). The gate-stack deposition was always preceded by an optimized number of cycles of a wet-chemistry based digital etch (DE) process [18] and a very smooth channel surface for high-k deposition was obtained: the substrates were cleaned in a $2 \mathrm{M} \mathrm{HCl}$ solution for $5 \mathrm{~min}$ at room temperature, and subsequently rinsed in de-ionized water.

The $\mathrm{Al}_{2} \mathrm{O}_{3}$ gate stack was deposited by ALD at $300{ }^{\circ} \mathrm{C}$, and TMA and $\mathrm{HfCl}_{4} / \mathrm{H}_{2} \mathrm{O}$ were used as precursors for $\mathrm{Al}_{2} \mathrm{O}_{3}$ and $\mathrm{HfO}_{2}$, respectively [19]. For the ASM-IL gate-stack, $\mathrm{H}_{2} \mathrm{~S}$ pretreatment and deposition of the ASM-IL (Inter Layer), $\mathrm{LaSiO}_{\mathrm{x}}$, and $\mathrm{HfO}_{2}$ were done in an ASM Pulsar ${ }^{\circledR} 3000$ ALD reactor. The $\mathrm{H}_{2} \mathrm{~S}$ pretreatment is done in-situ, prior to the high$\kappa$ deposition. The $\kappa$-value of the ASM-IL is $\sim 6$. The $\mathrm{H}_{2} \mathrm{~S}$ treatment and IL film deposition are both done at $250^{\circ} \mathrm{C}$. The gate metal was formed using PVD TiN, while the S/D contacts were formed using $\mathrm{Mo} / \mathrm{Al}$ for both gate-stacks. The gate-stack deposition was identical for MOSCAPs and MOSFETs.

Capacitance-Voltage (CV) measurements on MOSCAPs were performed using Agilent 4284A LCR meter and CurrentVoltage (IV) measurements on MOSFETs were performed using Keithley K2600 series SMUs. The eMSM [20] measurement scheme was used for both CV-BTI and IV-BTI

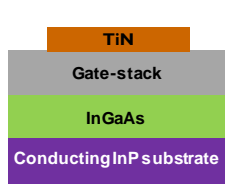

(a) MOSCAP

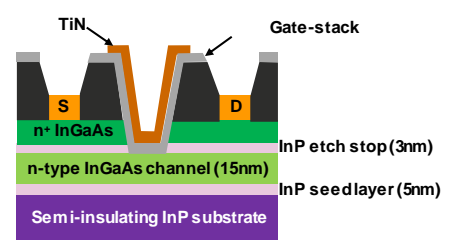

(b) MOSFET
Fig. 1. Schematic structure of the n-type InGaAs quantum well MOSFET used in this work.

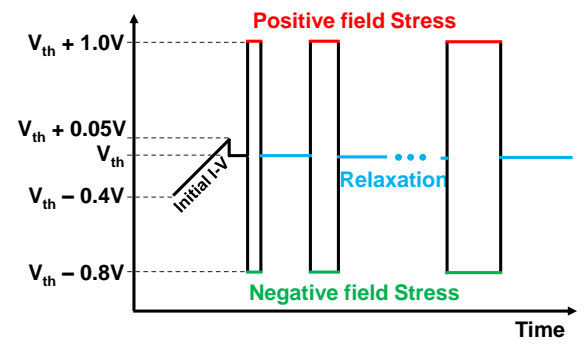

Fig. 2. Gate-voltage scheme for the eMSM experiment. Positive/negative gate stress bias is used to study shallow/deep defect distributions, respectively. experiments. $V_{G \text {,sense }}=V_{f b}\left(V_{t h}\right.$ for MOSFETs $)$ was used as the sense voltage during the relaxation phase. Increasing stress voltages, $V_{O V \text {,stress }}=V_{G}-V_{f b}$, was applied on the gate during the stress phase to study the PBTI kinetics of shallow oxide-defect energy states, while $V_{U N, \text { stress }}=V_{f b}-V_{G}$ was applied to study the NBTI kinetics of deep oxide-defect energy states. In the case of MOSFETs, the $V_{O V \text {,stress }}=1 \mathrm{~V}$ and $V_{U N \text {,stress }}=-0.8 \mathrm{~V}$ were applied respectively, for PBTI and NBTI stress (Fig. 2). The $V_{D S}$ was set to $50 \mathrm{mV}$ throughout the experiment to be able to sense a sizeable channel current.

All CV-BTI experiments were carried out at 298K, while for MOSFETs, the PBTI tests were performed at five different temperatures $(77 \mathrm{~K}, 233 \mathrm{~K}, 298 \mathrm{~K}, 373 \mathrm{~K}$ for model calibration, and $150 \mathrm{~K}$ for model verification), and NBTI tests were performed at $233 \mathrm{~K}, 298 \mathrm{~K}$ and $373 \mathrm{~K}$.

The reference threshold voltage $\left(V_{t h, r e f}\right)$ of a pristine deviceunder-test (DUT) was determined using max- $g_{m}$ method. In order to ensure the DUTs do not undergo any pre-stress degradation, BTI experiments were performed on a fresh MOSFET for each stress and temperature condition. A restricted $V_{G}$ sweep (from $V_{t h, \text { ref }}-0.4 \mathrm{~V}$ to $V_{t h \text {,ref }}+0.05 \mathrm{~V}$ ), was performed to determine the $V_{\text {th.DUT }}$, defined here as the voltage required to reach the threshold current of the reference DUT $\left(I_{D S} @ V_{t h, r e f}\right)$. BTI stress was subsequently applied for time periods ranging from $10 \mathrm{~ms}$ to $10 \mathrm{ks}$, with each stress phase followed by a relaxation phase of appropriate duration $(10 \mathrm{~ms}$ up to $100 \mathrm{ks}$ ). The drain current measured at a fixed sense $V_{G}$ $\left(=V_{t h, D U T}\right)$ during each relaxation phase from the BTI eMSM experiments, was used to extract the $\Delta V_{t h}$ [20].

\section{DEFECT BAND MODELLING}

The ground-state energy bands of defects for gate-stacks of MOSCAP devices (identical to that of MOSFET devices) were modelled as Gaussian distributions in the bandgap of an oxide with thickness corresponding to the equivalent oxide thickness of the real multi-layer stack.. The shift in flatband voltage $\left(\Delta V_{f b}\right)$ for positive (negative) BTI stress corresponds to the portion of the Gaussian distributions that is 'charged' ('discharged') by the Fermi level when gate-bias, $V_{\text {gate }}$, is switched between $V_{\text {relax }}$ and $V_{O V \text {,stress }}\left(V_{U N, \text { stress }}\right)$. It is also important to account for some part of the defect distribution that may be pre-charged, depending on the position of Fermi level at the flat-band condition.

It was shown in [21] that positive, as well as negative oxide field stress results in (+/-) $\Delta V_{f b}$, which entailed the inclusion of a deep defect energy distribution for gate-stacks of InGaAs devices, in addition to the shallow defect energy distribution. The total degradation under applied oxide stress field is then obtained as the sum of the individual contributions from the shallow and deep defect energy distributions. The generalized equation used to model the defect distribution and the degradation of $V_{f b}$ is given as [15],

$$
\left.N_{o t}=\int_{0}^{t o x}\left[\begin{array}{c}
\frac{1}{2}\left(1+\operatorname{erf}\left(\frac{E_{F}-\left(\mu_{a}-x \cdot E_{1}\right)}{\sqrt{2 \sigma_{a}^{2}}}\right)\right) \\
-\frac{1}{2}\left(1+\operatorname{erf}\left(\frac{E_{F}-\left(\mu_{n}-x \cdot E_{0}\right)}{\sqrt{2 \sigma_{a}^{2}}}\right)\right)
\end{array}\right] \times D_{o t, a}\right] d x
$$


where $t_{o x}=$ Capacitance equivalent oxide thickness, $x=$ distance from channel/oxide interface, $E_{F}=$ Fermi-energy level, $E_{0}$ and $E_{1}$ are the oxide fields at $V_{\text {Gate }}=V_{f b}$ and $V_{\text {Gate }}=V_{O V \text {,stress }}$ $\left(V_{U N, \text { stress }}\right)$, respectively, $\mu_{a}, \sigma_{a}$ and $D_{o t, a}$ are respectively, the mean, standard deviation and density of the Gaussian defect energy distribution.

The shallow and deep defect distributions are simultaneously evaluated, and calibrated to the experimental results of both PBTI and NBTI experiments as,

$$
\Delta V_{f b}=\frac{q}{\varepsilon_{0} \varepsilon_{r}}\left(N_{o t, \text { shallow }}-N_{o t, \text { deep }}\right)
$$

where $q=$ electronic charge $\left(1.6 \times 10^{19} \mathrm{C}\right), \varepsilon_{0}$ and $\varepsilon_{r}$ are respectively, the dielectric permittivity of free space and relative dielectric permittivity of $\mathrm{HfO}_{2}$. The resulting fits from the defect band modelling match excellently with the experimental results (Fig. 3).

The $\Delta V_{f b}$ can be converted to effective charging defect density $\Delta N_{\text {eff }}\left(\equiv \Delta V_{f b} \times\left(C_{o x} / q\right)\right.$, where $C_{o x}$ is the oxide capacitance), which is a parameter that is independent of the capacitance equivalent thickness. The field acceleration factor $(\gamma)$ defines the dependence of $\Delta N_{\text {eff }}$ on the equivalent oxide field $\left(E_{o x}\right)$ as $\Delta N_{e f f} \propto E_{o x}^{\gamma}$, and corresponds to the distribution of oxide defect energy levels. A higher $\gamma(>2.5)$ is favorable as it allows for lower $\Delta N_{\text {eff }}$ at operating $E_{o x}$. It can be seen in Fig. 4a that ASM-IL gate-stack shows higher $\gamma$ under both PBTI and NBTI stress conditions. As a result, the $\Delta N_{\text {eff }}$ in the ON state $\left(E_{o x, O N}=3.5 \mathrm{MV} / \mathrm{cm}\right)$ is obtained to be $3 \times 10^{11} \mathrm{~cm}^{-2}$ for $\mathrm{Al}_{2} \mathrm{O}_{3}$ gate-stack and $1.7 \times 10^{10} \mathrm{~cm}^{-2}$ for ASM-IL gate-stack (PBTI in Fig. 4a). Similarly, the $\Delta N_{\text {eff }}$ in the OFF state $\left(E_{\text {ox }, \text { OFF }}=1.67\right.$ $\mathrm{MV} / \mathrm{cm})$ is obtained as $1.6 \times 10^{11} \mathrm{~cm}^{-2}$ for $\mathrm{Al}_{2} \mathrm{O}_{3}$ gate-stack and $2.6 \times 10^{10} \mathrm{~cm}^{-2}$ for ASM-IL gate-stack (NBTI in Fig. 4a).

The large difference in the $\Delta N_{\text {eff }}$ can be easily understood by comparing the resulting ground-state oxide defect energy distributions (Fig. 4 b), i.e., for flat-band condition $\left(E_{o x}=0\right.$

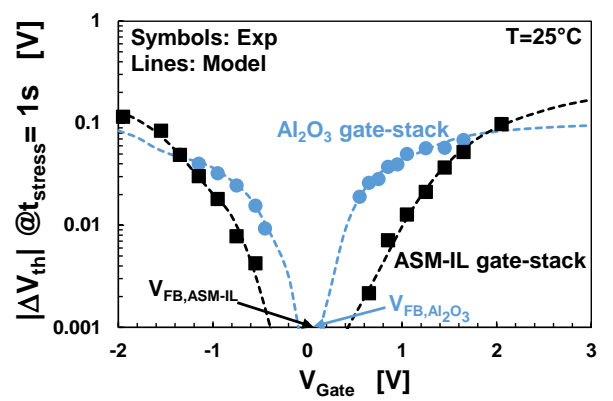

Fig. 3. The $V_{t h}$ degradation (symbols) under positive and negative oxide field stress is modeled (dashed lines) as a sum of contributions from the shallow and deep defect energy distributions under applied $E_{o x}$.

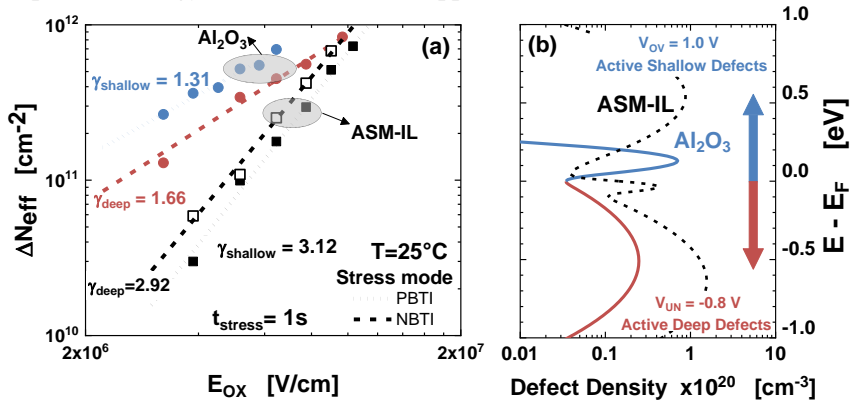

Fig. 4. (a) The effective charging density for ASM-IL gate-stack is extracted to be lower than that of $\mathrm{Al}_{2} \mathrm{O}_{3}$ under similar applied $E_{o x}$, and (b) Extracted groundstate defect bands extracted using the defect band model of [15].

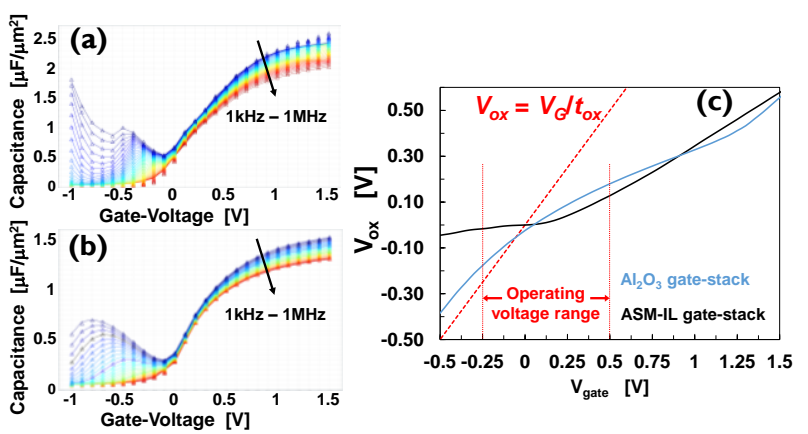

Fig. 5. The result of C-V fitting for (a) $\mathrm{HfO}_{2}$-based and (b) $\mathrm{Al}_{2} \mathrm{O}_{3}$-based gatestacks in MDLab; (c) The resulting dependence of the oxide potential, $V_{O X}$ vs. $V_{\text {Gate }}$. While $V_{F B}=0.05 \mathrm{~V}$ for both gate-stacks, the oxide field experienced by $\mathrm{Al}_{2} \mathrm{O}_{3}$ gate-stack is remarkably higher, especially in OFF-state operation, resulting in its higher OFF-state degradation compared to ASM-IL gate-stack.

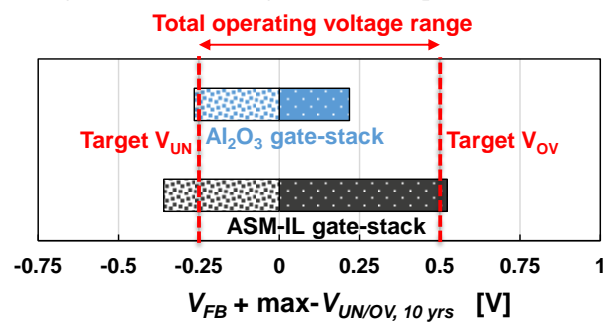

Fig. 6. Maximum operating overdrive $\left(V_{O V}\right)$ and underdrive $\left(V_{U N}\right)$ voltages to achieve a BTI lifetime of 10 years for the $\mathrm{Al}_{2} \mathrm{O}_{3}$ and ASM-IL gate-stacks. ASMIL gate-stack can achieve the required "Total operating voltage range" for III$\mathrm{V}$ technology with $V_{D D}=0.75 \mathrm{~V}$.

V/cm and $E-E_{F}=0 \mathrm{eV}$ ). The "Active Shallow Defect" states affect the ON-state reliability of the gate-stack. The shallow defect band of the $\mathrm{Al}_{2} \mathrm{O}_{3}$ gate-stack is located closer to $E-E_{F}$ $=0 \mathrm{eV}$, than that of the ASM-IL gate-stack. Therefore, the shallow defect states are easily accessible for a small applied oxide field. Similarly, the "Active Deep Defect" states limit the OFF-state reliability of the gate-stack. The increased defect energy range accessed during OFF-state for $\mathrm{Al}_{2} \mathrm{O}_{3}$ gate-stack, as a result of the increased $-V_{o x}$, is evident within the operating voltage range $\{-0.25 \mathrm{~V}, 0.5 \mathrm{~V}\}$ (Fig. 5). As a consequence, the larger defect energy range accessible under negative oxide field for $\mathrm{Al}_{2} \mathrm{O}_{3}$ gate-stack, albeit the density of the deep defect distribution for the $\mathrm{Al}_{2} \mathrm{O}_{3}$ gate-stack being lower as compared to that of ASM-IL gate-stack, causes significant charge trapping in the OFF-state $\left(E_{o x, O F F}=1.67 \mathrm{MV} / \mathrm{cm}\right)$. We note that a robust extraction of defect energy bands was possible by obtaining the $V_{o x}$ vs. $V_{\text {Gate }}$ relationship, after accounting for interface defects, through MDLab [22] using the Capacitance-Voltage (C-V) data of the different gate-stacks (Fig. 5a and Fig. 5b).

The "Total operating voltage range", defined as $\left\{\max -V_{U N}\right.$, max- $\left.V_{O V}\right\}$ to achieve BTI lifetime of 10 years (criteria: $\Delta V_{t h}=$ $30 \mathrm{mV}$ at $E_{\text {ox }, O N}$ and $E_{\text {ox }, O F F}, \mathrm{~T}=25^{\circ} \mathrm{C}$ ) [15], is thus obtained to be $\{-0.26 \mathrm{~V}, 0.21 \mathrm{~V}\}$ for the $\mathrm{Al}_{2} \mathrm{O}_{3}$ gate-stack and $\{-0.36 \mathrm{~V}$, $0.52 \mathrm{~V}\}$ for the ASM-IL gate-stack (Fig. 6). It is evident that the favourable defect configuration and lower active defect density at operating oxide fields $(\{-1.67 \mathrm{MV} / \mathrm{cm}, 3.5 \mathrm{MV} / \mathrm{cm}\})$ of the ASM-IL gate-stack enables the achievement of the target operating voltage range, $\{-0.25 \mathrm{~V}, 0.5 \mathrm{~V}\}$, for III- $\mathrm{V}$ logic technology with $V_{D D}=0.75 \mathrm{~V}$.

\section{CAPTURE AND EMISSION TIME (CET) MAP}

The Non-radiative Multiphonon (NMP) model is invoked to describe the trapping and de-trapping of channel carriers into 


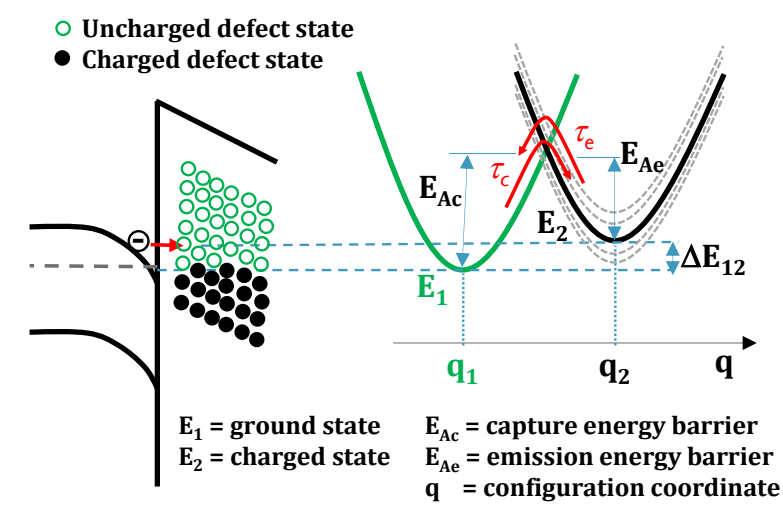

Fig. 7. Change in the energy and configuration of each defect state is captured with $E_{A}$ distribution. The vibrational energy of the system (Huang-Rhys factor, lattice relaxation energy, and capture cross section) can be captured by modelling an effective $E_{A}$ with a Gaussian distribution (adapted from [23]).

border traps as well as traps located deeper into the dielectricstack [23]. According to the NMP model, charge (de-)trapping process involves inelastic tunneling between the channel and the defect site, as thermal energy is required to reorganize the atoms at the defect site for accommodating the additional charge. The energy barrier for the capture and emission process are modulated by the applied bias.

As illustrated in Fig. 7, for an electron to tunnel from the channel (at energy state $E_{1}$ ) to a defect site in the oxide (at energy state $E_{2}$ ), at least the ground-state electrostatic energy barrier $\left(\Delta E_{12}\right)$ must be overcome by applying a suitable gatebias. However, the effective time constant for capture $\left(\tau_{c}\right)$ or emission $\left(\tau_{c}\right)$ of the charge carrier, that tunnels inelastically between the channel and the defect state, is further dependent on the effective activation energy required for the capture process, $E_{A c}$, or emission process, $E_{A e}$, and requires accounting for the vibrational energy of the system as well. Therefore, the effective capture and emission times ( $\tau_{c}$ and $\tau_{c}$ ) of oxide defects, which correspond to the experimental stress and relaxation times, can be approximately represented as [23],

$$
\tau_{c}=\tau_{0} e^{\frac{E_{A c}}{k_{B} T}} \quad \text { and } \quad \tau_{e}=\tau_{0} e^{\frac{E_{A e}}{k_{B} T}}
$$

where $k_{B}=$ the Boltzmann constant, $T=$ the absolute temperature, and $\tau_{0}=$ effective time constant that incorporates the carrier concentration, elastic tunneling probability and trap capture cross section, and is weakly dependent on bias and temperature.

As the vibrational state of the system is stochastic in nature, the effective activation energies $\left(E_{A c}\right.$ and $\left.E_{A e}\right)$, and the resulting time constants $\left(\tau_{c}\right.$ and $\left.\tau_{e}\right)$ obtained for charge capture (or, emission) for the defects with identical ground-state energy are distributed. This distribution of $E_{A c}$ and $E_{A e}$ is modelled as a bivariate Gaussian distribution with distribution parameters $\left\{\mathrm{x}_{\mathrm{c},} \mathrm{X}_{\mathrm{e}}\right\}$ as,

$$
\begin{aligned}
& F\left(E_{A c}, E_{A e}\right)=\frac{1}{2 \pi \sigma_{c} \sigma_{e} \sqrt{1-\rho^{2}}} \exp \left[-\frac{z}{2\left(1-\rho^{2}\right)}\right] \\
& \text { with, } \quad Z=\frac{\left(x_{c}-\mu_{c}\right)^{2}}{\sigma_{c}^{2}}-\frac{2 \rho\left(x_{c}-\mu_{c}\right)\left(x_{e}-\mu_{e}\right)}{\sigma_{c} \sigma_{e}}+\frac{\left(x_{e}-\mu_{e}\right)^{2}}{\sigma_{e}^{2}} \\
& \text { and, } \quad \rho=\frac{\operatorname{covariance}\left(x_{c}, x_{e}\right)}{\sigma_{c} \sigma_{e}}
\end{aligned}
$$

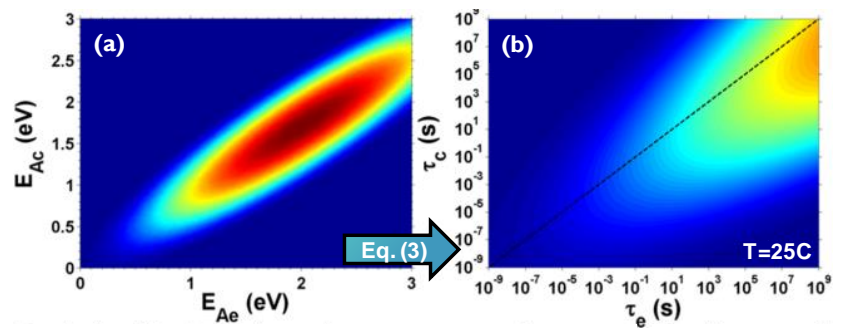

Fig. 8. (a) Bivariate Gaussian distribution of capture/emission energy barriers calibrated for a commercial Si n-MOSFET [24], (b) which is translated into a corresponding Capture/Emission Time (CET) map.

The bivariate Gaussian distribution is described by its mean $\left\{\mu_{c}, \mu_{e}\right\}$ and standard deviation $\left\{\sigma_{c}, \sigma_{e}\right\}$, while $\rho$ is the correlation parameter for the two associated Gaussian distributions of activation energies for capture and emission processes. The total $\Delta V_{t h}$ can then be calculated as,

$$
\Delta V_{t h}=A \int_{0}^{E_{c}} \int_{E_{e}}^{\infty} F\left(E_{A c}, E_{A e}\right) d E_{A c} d E_{A e}
$$

where, $A=$ scaling parameter, $E_{c}$ and $E_{e}=$ activation energy corresponding to the experimental stress and relaxation times (from Eq. (3)), respectively. An example of such an activation energy map, calibrated to the BTI results of an Si-nMOS device [24] is shown in Fig. 8a. The corresponding Capture/Emission Time (CET) map is obtained by translating the activation energies to capture and emission times using Eq. (3) (Fig. 8b).

The NMP model is shown to effectively reproduce the wide distribution of charge capture and emission time constants under a uniform gate-stack stress. Therefore, the various experimentally observed features such as the frequency dispersion of the capacitance-voltage characteristics in strong accumulation [25], and the complex bias and temperature dependence of charge trapping can be accurately modeled to obtain the effective defect energy distributions. The capture and emission activation energy distributions thus obtained, are crucial for prediction of the kinetics of BTI degradation and the device operating lifetime under $\mathrm{AC}$ and DC operation.

The kinetics of charge (de-)trapping can be illustrated with a simple simulation based on the NMP model, and its impact on $V_{t h}$ under different operating conditions can be studied. The defects with identical bias-dependent ground-state energies ('Defect-band modelling' [15] method in Section III) can be shown to exhibit different capture/emission time constants based on their capture/emission activation energy barriers. Fig. 9a and Fig. 9e show the 2-state potential energy landscapes for two defects, Type- 1 and Type-2, respectively. Their neutral and charged states are modelled with ground-state energies, $E_{1}$ and $E_{2}$, respectively. The defect is charged when the applied bias surpasses the electrostatic energy barrier $\Delta E_{12}$, and the time taken for the defect to be charged (or discharged) depends on the activation energy $E_{A c 1}$ (or $E_{A e 1}$ ) for Type-1 defect, and $E_{A c 2}$ (or $E_{A e 2}$ ) for Type-2 defect.

Gaussian distribution of the parameters $E_{A c}$ and $E_{A e}$ results in a bivariate distribution of activation energies as shown in Fig. $9 \mathrm{~b}$ and Fig. 9f for Type-1 and Type- 2 defects, respectively. Note that the average activation energies for capture $\left(\mu_{E A c}\right)$ and emission $\left(\mu_{E A e}\right)$ are different for the two defect types, while the 


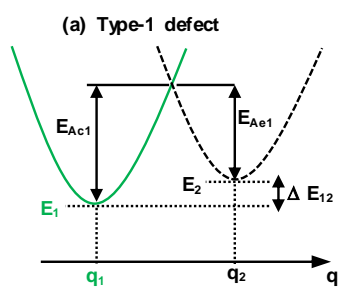

$E_{A C}=$ capture energy barrier $E_{\mathrm{Ae}}=$ emission energy barrie $E_{1}=$ ground state (Neutral) $\mathrm{E}_{2}=$ ground state (Charged) $\mathrm{q}=$ configuration coordinate

(e) Type-2 defect

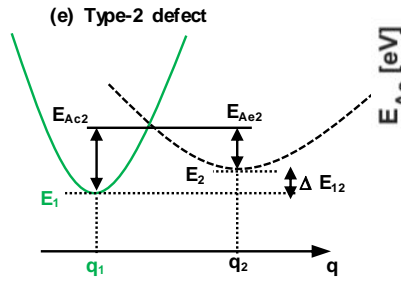

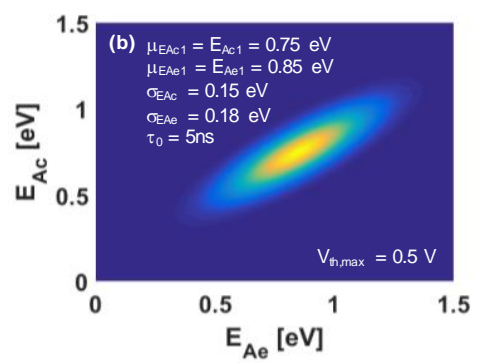
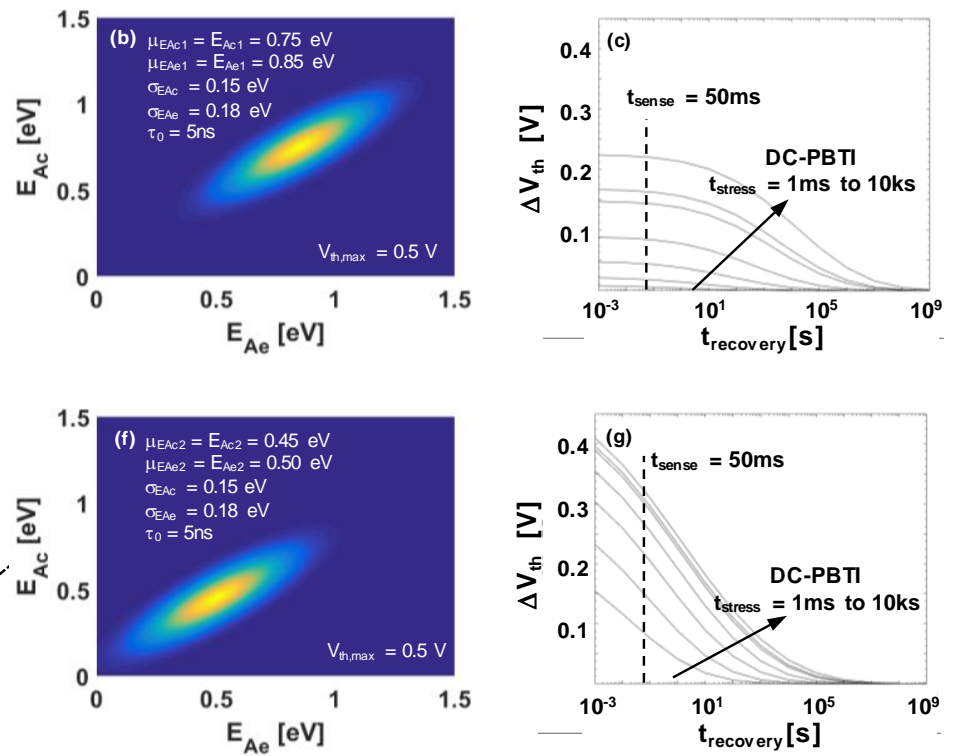
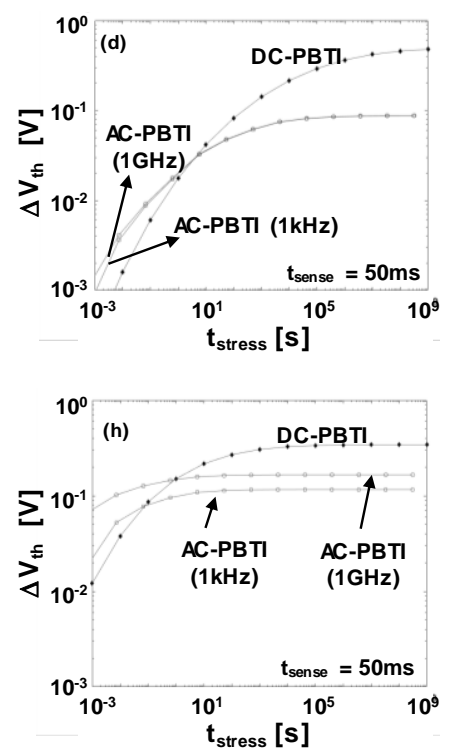

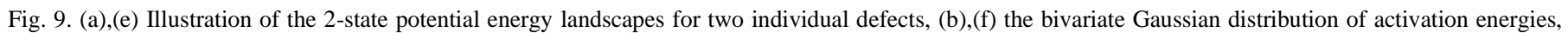

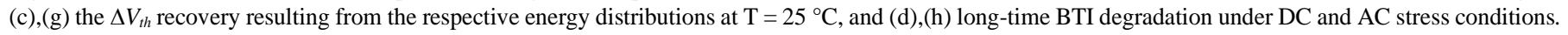

other parameters of bivariate Gaussian distributions, namely, the standard-deviation of capture $\left(\sigma_{E A C}\right)$ and emission activation energies $\left(\sigma_{E A e}\right)$, the pre-factor $\left(\tau_{0}\right)$, and the total defect density (represented by an equivalent parameter, $\Delta V_{t h, \max }$ ) are identical. It is evident that Type-2 defects will have short capture and emission time constants compared to the Type- 1 defects, due to their low capture and emission activation energies.

Consequently, the 'fast' Type-2 defects will result in larger $\Delta V_{t h}$ compared to the relatively 'slow' Type-1 defects which can be observed in Fig. 9c and Fig. $9 \mathrm{~g}(\sim 0.22 \mathrm{~V}$ for Type-1 vs. $\sim 0.42$ $\mathrm{V}$ Type- 2 for $t_{\text {stress }}=10 \mathrm{ks}$, at the beginning of recovery phase). Due to the lower emission activation energy of Type-2 defects, they are also observed to recover faster than Type-1 defects ( $\Delta V_{\text {th }}$ recovers almost completely in $\sim 10^{5}$ s for Type-2, while considerable $\Delta V_{t h}$ is remnant at $\sim 10^{5} \mathrm{~s}$ for Type-1, when the recovery trends after $t_{\text {stress }}=10 \mathrm{ks}$ are compared). Finally, the total degradation of $V_{\text {th }}$ after $\mathrm{DC}$ and $\mathrm{AC}(1 \mathrm{kHz}$ and $1 \mathrm{GHz})$ BTI stress and sense delay ( $\left.t_{\text {sense }}\right)$ of $50 \mathrm{~ms}$ is shown in Fig. 9d and Fig. 9h for Type-1 and Type- 2 defects, respectively.

The following conclusions can be drawn: (a) long-time degradation under DC-BTI stress is higher for Type-1 defects, since a considerable portion of the defect population is not discharged in $50 \mathrm{~ms}$ due to the higher $E_{A e 1}$ as compared to Type2 defects; (b) since the Type-1 defects are 'slow', with capture and emission rates $\left(1 / \tau_{c}\right.$ and $\left.1 / \tau_{e}\right)$ of a large portion of the defect distribution being smaller than the applied frequencies $(1 \mathrm{kHz}$ $1 \mathrm{GHz}$ ), the degradation due to AC-BTI stress appears to be frequency independent and lower (because these defects do not get charged) compared to that from the 'fast' Type-2 defects; and (c) a clear frequency dependence of long-time BTI degradation is seen for the 'fast' Type-2 defects since the capture and emission rates $\left(1 / \tau_{c}\right.$ and $\left.1 / \tau_{e}\right)$ of these defects fall within the applied frequency range.

This exercise clearly demonstrates the necessity to accurately characterize the activation energies of charge capture and emission for defects in gate-stacks of III-V devices to study their BTI kinetics. It will be shown in Section V that a total of three defect sub-populations, with different properties, are required to describe the BTI degradation of the ASM-IL based gate-sack.

\section{CET MAPS FOR $\mathrm{Al}_{2} \mathrm{O}_{3}$ AND ASM-IL GATE-STACK}

Extensive BTI measurements were performed on MOSFETs with the $\mathrm{Al}_{2} \mathrm{O}_{3}$ and ASM-IL based gate-stacks, with stress bias $V_{O V \text {,stress }}=1 \mathrm{~V}$ for positive field stress and $V_{U N \text {,stress }}=-0.8 \mathrm{~V}$ for negative field stress, while the bias during relaxation $V_{\text {relax }}=$ $V_{t h, D U T}$ was used during both the type of BTI experiments. The experiments were carried out at $\mathrm{T}=-40{ }^{\circ} \mathrm{C}, 25^{\circ} \mathrm{C}, 100{ }^{\circ} \mathrm{C}$ (and additionally at $\mathrm{T}=77 \mathrm{~K}$ for $V_{O V \text {,stress }}=1 \mathrm{~V}$ ) using the eMSM scheme of Fig. 2. The resulting $\Delta V_{t h}$ vs $t_{\text {relax }}$ data for the $\mathrm{Al}_{2} \mathrm{O}_{3}$ gate-stack are shown in Fig. 10a-c (black circles) for PBTI stress and Fig. 10d-f (black circles) for NBTI stress at $\mathrm{T}=-40$ ${ }^{\circ} \mathrm{C}, 25{ }^{\circ} \mathrm{C}, 100{ }^{\circ} \mathrm{C}$, respectively [24]. Similarly, the resulting $\Delta V_{\text {th }}$ vs $t_{\text {relax }}$ data for the ASM-IL gate-stack are shown in Fig. 11a-c (black circles) for PBTI stress and Fig. 11d-f (black circles) for NBTI stress at $\mathrm{T}=-40{ }^{\circ} \mathrm{C}, 25{ }^{\circ} \mathrm{C}, 100{ }^{\circ} \mathrm{C}$, respectively.

The recovery trends of $\Delta V_{t h}$ in Fig. 10 and Fig. 11 depict very similar features, related to the presence of two relaxation slopes after positive and negative stress phases. However, the $\Delta V_{t h}$ at the end of every relaxation phase after positive stress is comparatively lower for ASM-IL based gate-stack than $\mathrm{Al}_{2} \mathrm{O}_{3-}$ based gate-stack, indicating a better reliability at high oxide fields (fast defects). On the other hand, the $\Delta V_{t h}$ degradation is marginally higher for ASM-IL based gate-stack when subjected to large negative oxide stress. This is in agreement with the BTI characterization and benchmarking results presented in Section III, which showed that the $\Delta N_{\text {eff,deep }} @ E_{o x}=\sim 5 \mathrm{MV} / \mathrm{cm}$ is similar for the $\mathrm{Al}_{2} \mathrm{O}_{3}$ and ASM-IL gate-stacks, but due to the higher $\gamma_{\text {deep }}$ of ASM-IL gate-stack, it was shown to result in a better $\max -V_{O V, 10 y r s}$ and max- $V_{U N, 10 y r s}[15]$. 

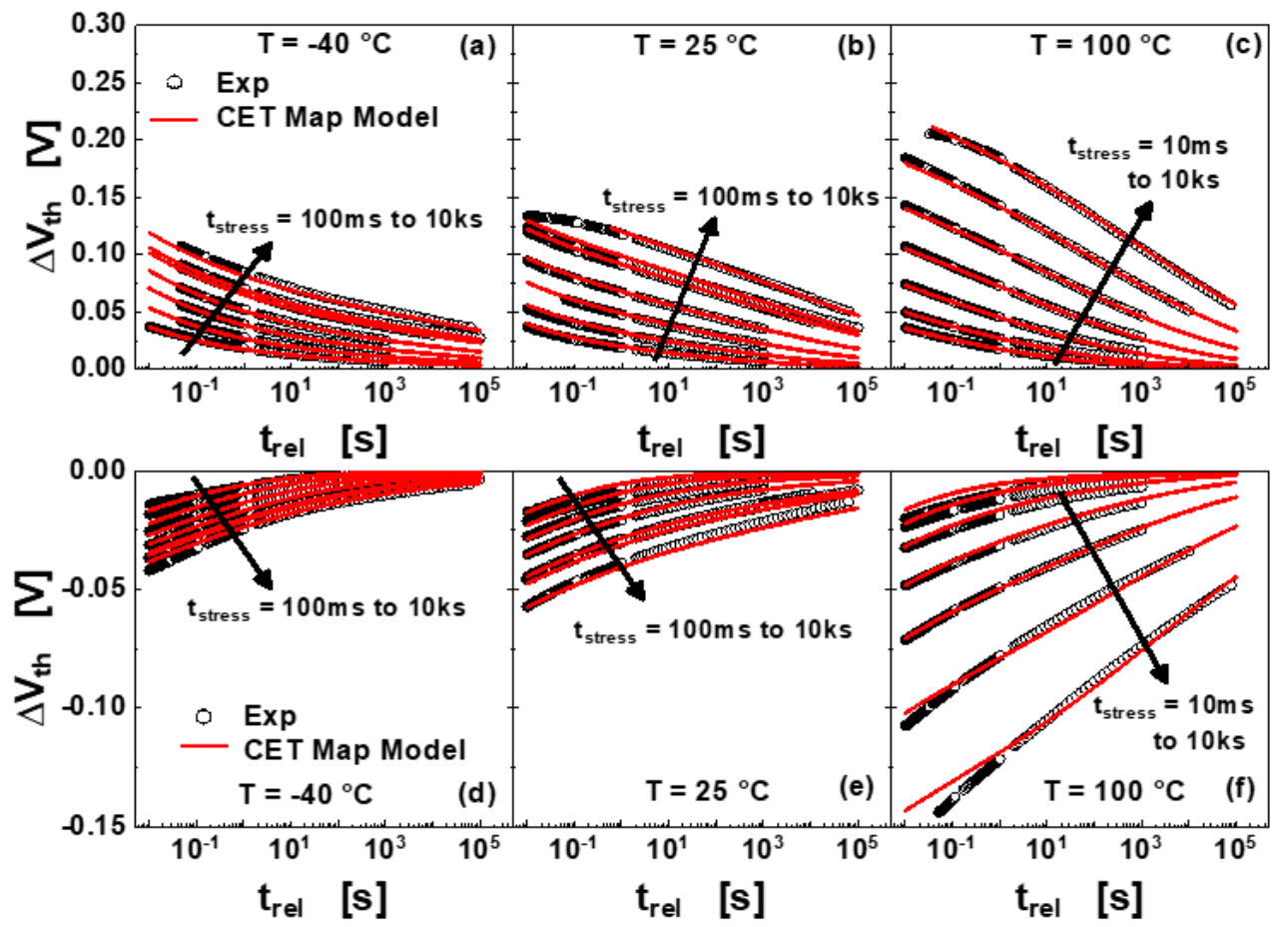

Fig. 10. $\mathbf{A l}_{2} \mathbf{O}_{3}$ gate-stack: The $\Delta V_{t h}$ recovery is shown for positive stress with $V_{o v}=1.0 \mathrm{~V}$ (figures a-c) and negative stress with $V_{u n}=-0.8 \mathrm{~V}$ (figures d-f) for $\mathrm{T}=-$ $40{ }^{\circ} \mathrm{C}, 25^{\circ} \mathrm{C}$ and $100{ }^{\circ} \mathrm{C}$. The symbols are experimental data and red lines are the result of the $\Delta V_{t h}$ calculated from the CET map model, with fitted parameters from Table I.
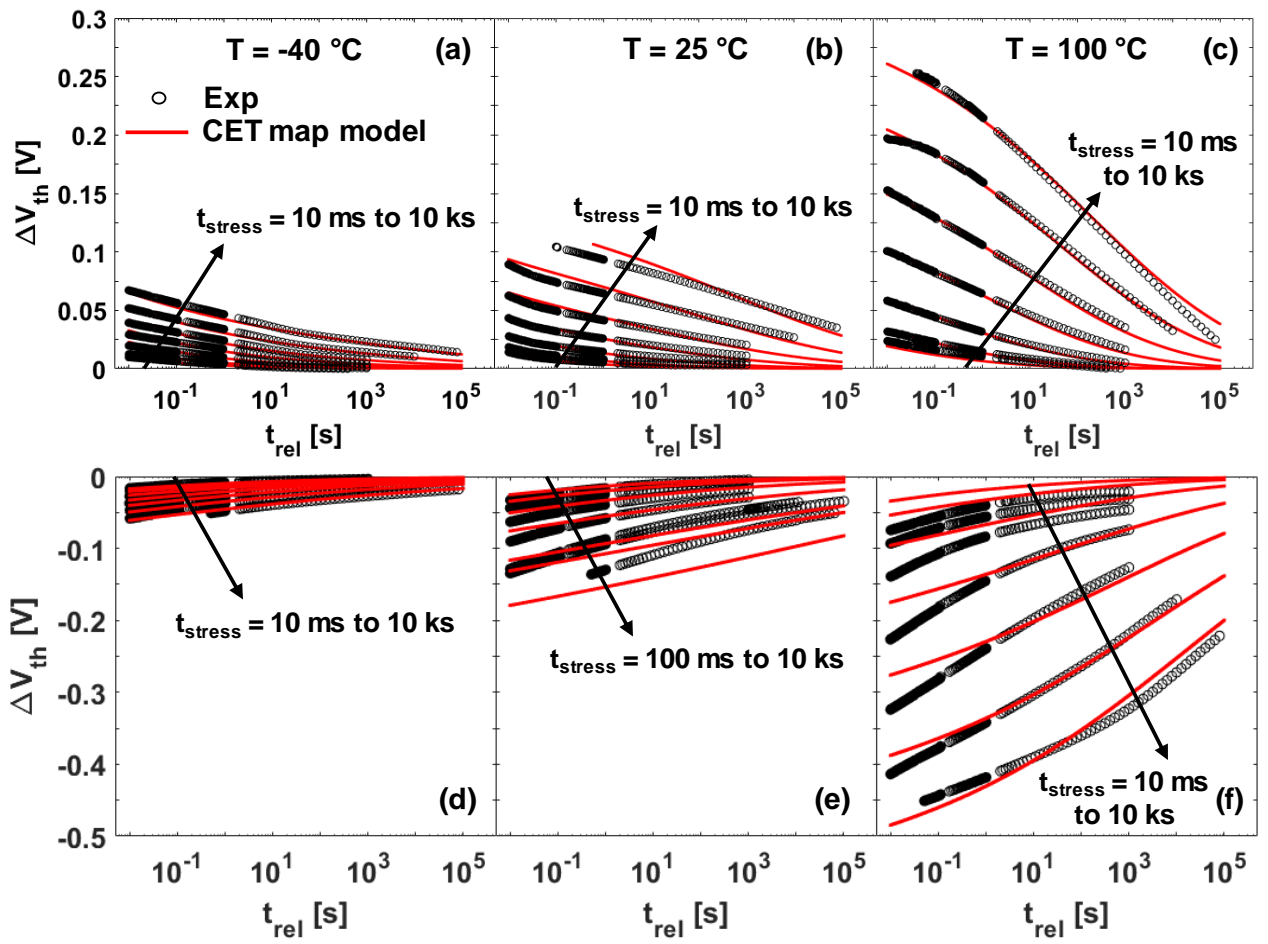

Fig. 11. ASM-IL gate-stack: The $\Delta V_{t h}$ recovery is shown for positive stress with $V_{o v}=1.0 \mathrm{~V}$ (figures a-c) and negative stress with $V_{u n}=-0.8 \mathrm{~V}$ (figures d-f) for T $=-40{ }^{\circ} \mathrm{C}, 25^{\circ} \mathrm{C}$ and $100{ }^{\circ} \mathrm{C}$. The symbols are experimental data and red lines are the result of the $\Delta V_{t h}$ calculated from the CET map model, with fitted parameters from Table I.

The results of PBTI experiments at $\mathrm{T}=77 \mathrm{~K}$ are presented in Fig. 12 (black symbols). Significant temperature dependence of $\Delta V_{t h}$ is evident by comparing the absolute values at the different temperatures. In order to model the temperature dependence of BTI in the $\mathrm{Al}_{2} \mathrm{O}_{3}$ and ASM-IL gate-stacks, the CET map modelling technique [16] described in Section IV is used to construct the activation energy map for the capture and emission process (Fig. 13a for $\mathrm{Al}_{2} \mathrm{O}_{3}$ and Fig. 13b for ASM-IL gate-stack). The results after optimization of all defect subpopulations are observed to reproduce the experimental data excellently (shown as red lines in Fig. 10 for $\mathrm{Al}_{2} \mathrm{O}_{3}$ gate-stack and Fig. 11 ASM-IL gate-stack).

The optimized set of parameters for 'Fast' and 'Slow' defect sub-populations are presented in Table I ('Shallow' defects) and 

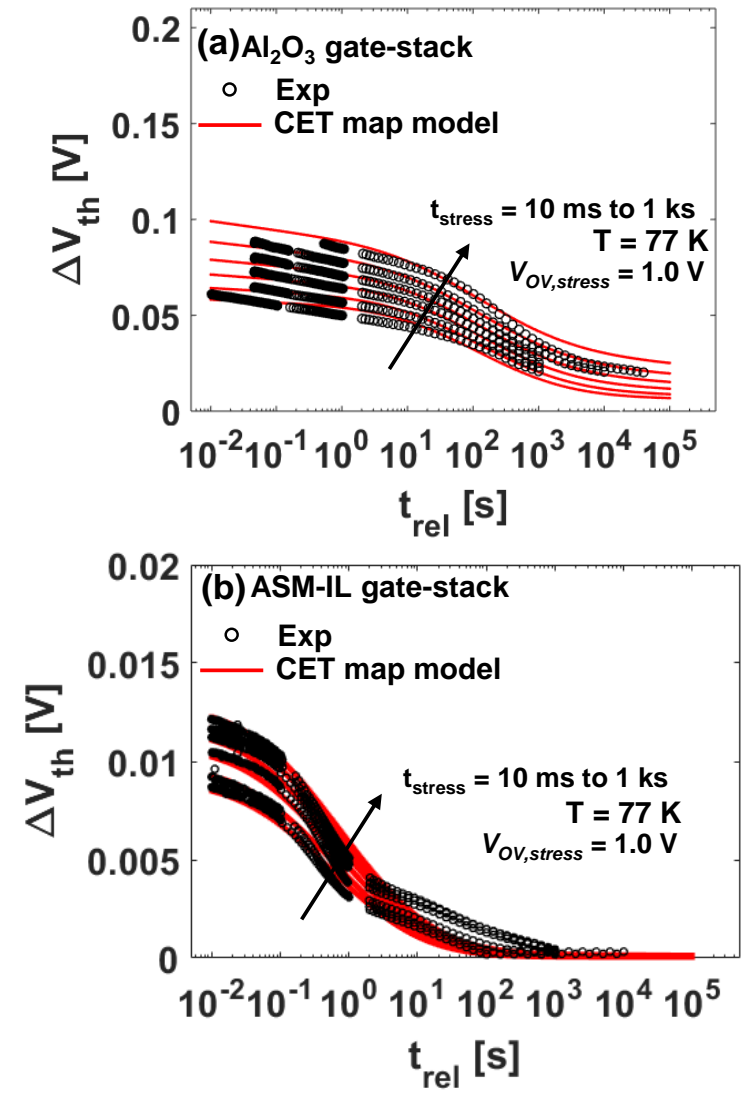

Fig. 12. Experimental results (symbols) showing the relaxation of $\Delta V_{t h}$ vs. $t_{\text {relax }}$ for (a) the $\mathrm{Al}_{2} \mathrm{O}_{3}$ and (b) ASM-IL gate-stacks at $\mathrm{T}=77 \mathrm{~K}$. The symbols are experimental data and the red lines are the results obtained by calibrating respective R3 components (Fig. 13).

TABLE I

OPTIMIZED PARAMETER SET FOR 'SHALLOW DEFECTS'

\begin{tabular}{|c|c|c|c|c|c|c|}
\hline \multirow[b]{2}{*}{ Parameter } & \multicolumn{3}{|c|}{ ASM-IL based gate-stack } & \multicolumn{3}{|c|}{$\mathrm{Al}_{2} \mathrm{O}_{3}$ based gate-stack $[16$} \\
\hline & $\begin{array}{l}\mathrm{R} 1 \\
\text { 'Slow' }\end{array}$ & $\mathrm{R} 2$ & $\begin{array}{ll}\mathrm{R} 3 \\
t^{\prime}\end{array}$ & $\begin{array}{c}\mathrm{R} 1 \\
\text { 'Slow' }\end{array}$ & & $\begin{array}{l}\mathrm{R} 3 \\
\text { st' }\end{array}$ \\
\hline$\left\langle\mathrm{E}_{\mathrm{Ac}}\right\rangle(\mathrm{eV})$ & 1.0 & 0.40 & 0.04 & 0.89 & 0.21 & 0.05 \\
\hline$\sigma_{\mathrm{Ec}} \quad(\mathrm{eV})$ & 0.24 & 0.08 & 0.06 & 0.40 & 0.08 & 0.03 \\
\hline$\left\langle\mathrm{E}_{\mathrm{Ae}}\right\rangle(\mathrm{eV})$ & 1.05 & 0.21 & 0.09 & 1.00 & 0.16 & 0.14 \\
\hline$\sigma_{\mathrm{Ee}} \quad(\mathrm{eV})$ & 0.29 & 0.16 & 0.02 & 0.45 & 0.15 & 0.02 \\
\hline$\tau_{0} \quad(\mathrm{~ns})$ & 0.03 & 0.14 & 557.4 & 22.4 & 0.93 & 70.55 \\
\hline$\Delta \mathrm{V}_{\mathrm{th}, \max }(\mathrm{V})$ & 0.47 & 0.18 & 0.013 & 0.60 & 0.21 & 0.05 \\
\hline
\end{tabular}

TABLE II

OPTIMIZED PARAMETER SET FOR 'DEEP DEFECTS'

\begin{tabular}{|c|c|c|c|c|}
\hline \multirow[t]{2}{*}{ Parameter } & \multicolumn{2}{|c|}{ ASM-IL based gate-stack } & \multicolumn{2}{|c|}{$\begin{array}{c}\mathrm{Al}_{2} \mathrm{O}_{3} \text { based gate-stack } \\
{[16]}\end{array}$} \\
\hline & 'Slow' & 'Fast' & 'Slow' & 'Fast' \\
\hline$\left\langle\mathrm{E}_{\mathrm{Ac}}\right\rangle(\mathrm{eV})$ & 1.08 & 0.28 & 1.5 & 0.15 \\
\hline$\sigma_{\mathrm{Ec}} \quad(\mathrm{eV})$ & 0.15 & 0.63 & 0.33 & 0.16 \\
\hline$\left\langle\mathrm{E}_{\mathrm{Ae}}\right\rangle(\mathrm{eV})$ & 1.29 & 0.26 & 1.61 & 0.19 \\
\hline$\sigma_{\mathrm{Ee}} \quad(\mathrm{eV})$ & 0.27 & 0.67 & 0.4 & 0.18 \\
\hline$\tau_{0} \quad(\mathrm{~ns})$ & 0.0005 & 30.97 & 0.53 & 75 \\
\hline$\Delta \mathrm{V}_{\text {th,max }}(\mathrm{V})$ & 0.53 & 0.32 & 0.77 & 0.08 \\
\hline
\end{tabular}

Table II ('Deep' defects), along with those obtained for the $\mathrm{Al}_{2} \mathrm{O}_{3}$-based gate-stack [16]. The $\left\langle E_{A c}\right\rangle$ and $\left\langle E_{A e}\right\rangle$ parameters for the 'Slow' sub-population of the deep defect distribution are smaller for ASM-IL based gate-stack as compared to $\mathrm{Al}_{2} \mathrm{O}_{3^{-}}$ based gate-stack (directly correlated with its closer proximity to the $E_{F}$ at flat-band condition), impacting the OFF-state performance.
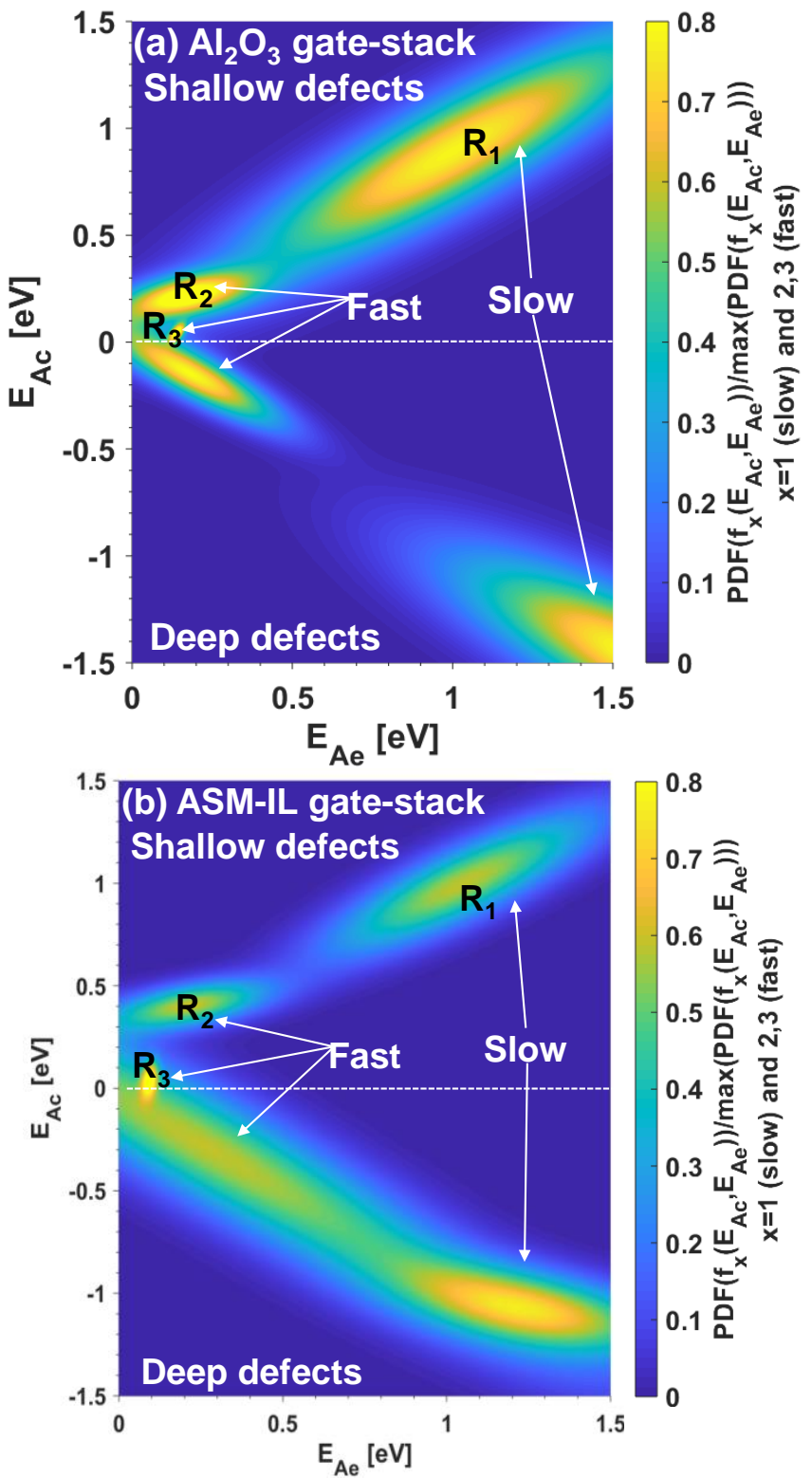

Fig. 13. The optimized activation energy map for defect capture and emission barriers for (a) the $\mathrm{Al}_{2} \mathrm{O}_{3}$ and (b) ASM-IL gate-stacks. A combination of three defect sub-populations $\left(\mathrm{R}_{1}-\right.$ slow and $\mathrm{R}_{2}, \mathrm{R}_{3}-$ fast $)$ are required to describe the complete shallow defect states' distribution and to accurately reproduce the $\Delta V_{\text {th }}$ relaxation transients across the entire temperature range ( $77 \mathrm{~K}$ to $\left.373 \mathrm{~K}\right)$. The deep defect states' distribution, on the other hand, is described by two sub-populations (fast and slow). The positive and negative $E_{A c}$ scale denote the activation energy barriers for 'capture' into the shallow defect states (above $E_{F}$ ), and for 'capture' into deep defect states (below $E_{F}$ ), respectively.
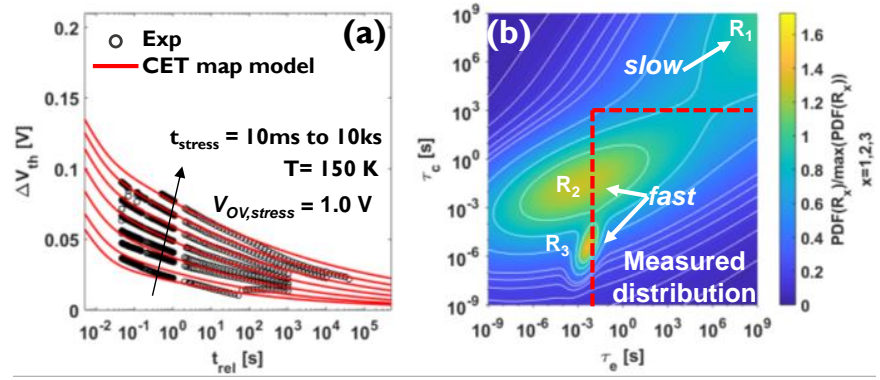

Fig. 14. (a) $\Delta V_{t h}$ data predicted at $\mathrm{T}=150 \mathrm{~K}$ (red lines) from the optimized activation energy map of $\mathrm{Al}_{2} \mathrm{O}_{3}$ gate-stack (Fig. 13a), are seen to match excellently with the experimental results at $\mathrm{T}=150 \mathrm{~K}$ (black circles), and (b) the predicted CET map confirms that the $\mathrm{R}_{3}$ component could be overlooked if the experiments are performed at $\mathrm{T}>150 \mathrm{~K}$. 
In order to ascertain the confidence in the optimized parameters, the optimized activation energy map of the $\mathrm{Al}_{2} \mathrm{O}_{3}$ gate-stack (Fig. 13a) was used to predict the degradation at an arbitrarily chosen temperature of $\mathrm{T}=150 \mathrm{~K}$ (red lines in Fig. 14a). The BTI experiments were also performed at $\mathrm{T}=150 \mathrm{~K}$, and the resulting experimental $\Delta V_{t h}$ relaxation data (black circles in Fig. 14a) were compared to the predicted data. It is evident from Fig. 14 that there is an excellent match between the prediction and experiments. The CET map obtained for $\mathrm{T}=$ $150 \mathrm{~K}$ (Fig. 14b) depicts that the $\mathrm{R}_{3}$ sub-population is at the edge of the "measurable region" and could be elusive at higher temperatures. The temperature dependence of the different defect sub-populations can be further understood by visualizing

the CET maps for the calibrated temperatures.

\section{RESULTS AND DISCUSSION}

\section{A. Active defect sub-populations under DC-operation}

The CET maps for positive oxide stress are shown in Fig. 15a-d and those for negative oxide stress are shown in Fig. 15e$\mathrm{g}$ for the $\mathrm{Al}_{2} \mathrm{O}_{3}$ gate-stack [16,24]. Similarly, Fig. 16a-d and Fig. 16e-g show the CET maps for positive and negative oxide stress, respectively, for the ASM-IL gate-stack. The region demarcated as 'Measured distribution' shows the part of 'Fast' and 'Slow' defect populations that contribute to the experimentally measured $V_{t h}$ degradation.
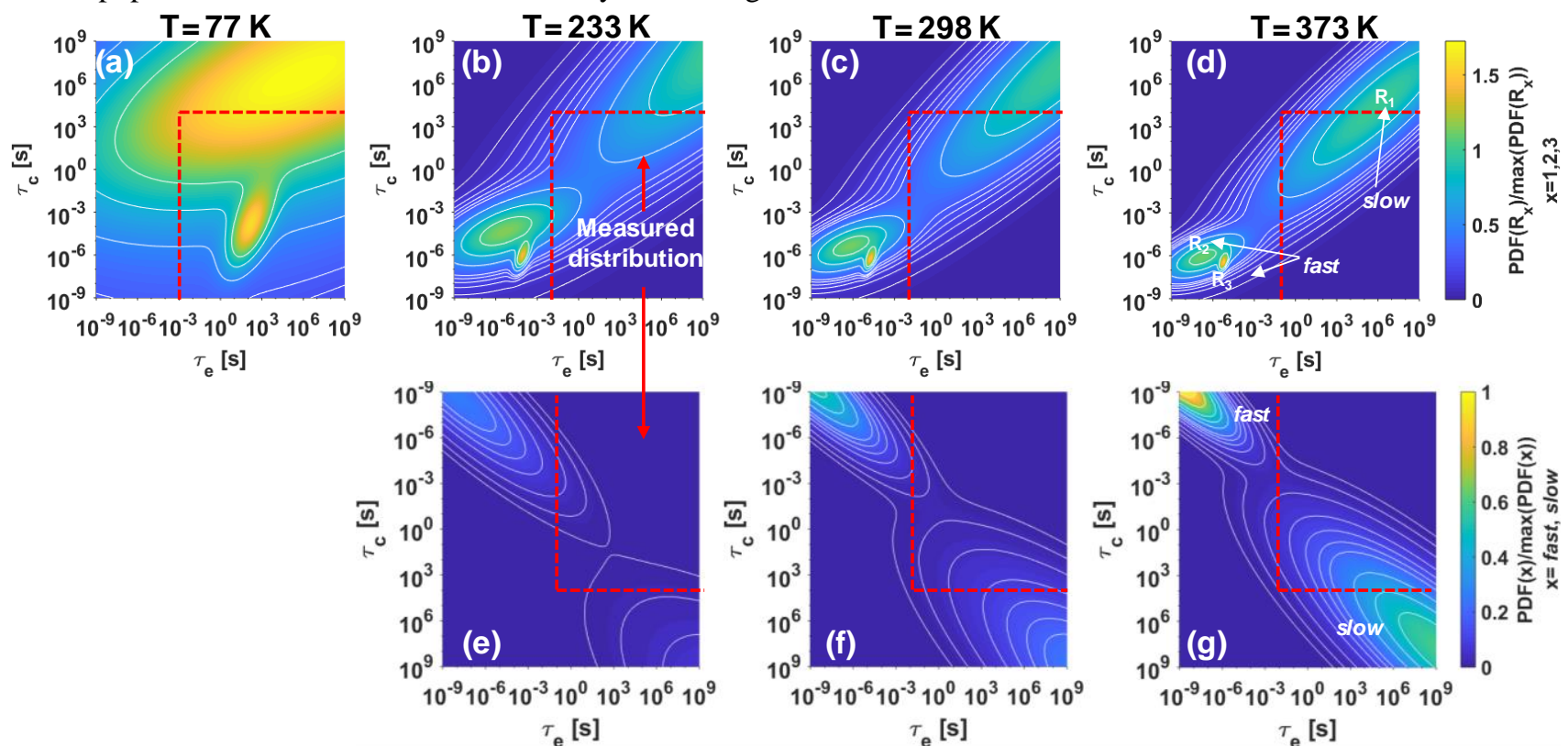

Fig. 15. $\mathbf{A l}_{2} \mathbf{O}_{3}$ gate-stack: The CET maps calculated from the activation energy distribution map of Fig. 12a for positive stress with $\mathrm{V}_{\mathrm{ov}}=1.0 \mathrm{~V}$ (figures a-c) and negative stress with $\mathrm{V}_{\mathrm{un}}=-0.8 \mathrm{~V}$ (figures d-f). The regions demarcated as 'Measured Distribution' represent the portions of the defect distributions that contribute to the experimentally measured $\Delta V_{t h}$. NOTE: The $\tau_{\mathrm{c}}$ axis of figures $\mathrm{d}$, e and $\mathrm{f}$ is reversed to represent deep defect states. Color scale may be used to understand the relative height and spread of defect populations. The contribution of individual sub-populations to measured $\Delta V_{\text {th }}$ is summarized in Tables I \& II ( $\left.\Delta V_{\text {th,max }}\right)$.
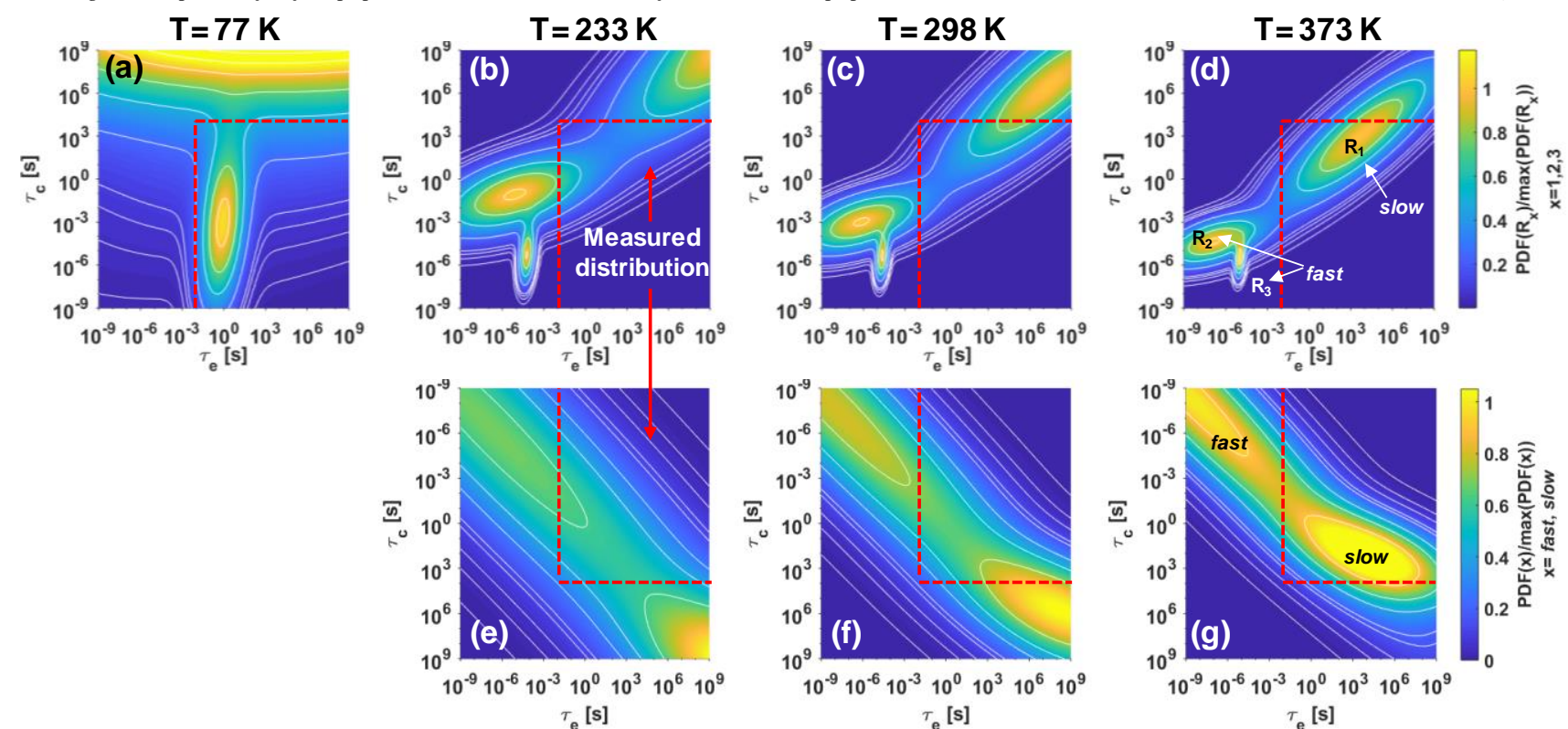

Fig. 16. ASM-IL gate-stack: The CET maps calculated from the activation energy distribution map of Fig. $12 \mathrm{~b}$ for positive stress with $\mathrm{V}_{\mathrm{ov}}=1.0 \mathrm{~V}$ (figures a-c) and negative stress with $\mathrm{V}_{\mathrm{un}}=-0.8 \mathrm{~V}$ (figures d-f). The regions demarcated as 'Measured Distribution' represent the portions of the defect distributions that contribute to the experimentally measured $\Delta V_{t h}$. 
It is evident again for both the gate-stacks, that only the 'Slow' defect populations are measurable at $\mathrm{T}=373 \mathrm{~K}$ (Fig. 15d,g and Fig. 16d,g), while only the 'Fast' defect populations contribute to the $V_{t h}$ degradation at $\mathrm{T}=77 \mathrm{~K}-233 \mathrm{~K}$ (Fig. 15a,b,e and Fig. 16a,b,e). The $\mathrm{R}_{3}$ component dominates the contribution to $\Delta V_{\text {th }}$ at $\mathrm{T}=77 \mathrm{~K}$ (Fig. 15a and Fig. 16a), as $\mathrm{R}_{1}$ is too slow to affect the device during its lifetime and contribution of $R_{2}$ component occurs only for very long stress durations $\left(\tau_{c}>10^{5} \mathrm{~s}\right)$. As the temperature is increased, the elusive $\mathrm{R}_{3}$ component becomes too fast and cannot be measured experimentally. When the temperature is raised to $373 \mathrm{~K}$, even the $R_{2}$ component is seen to shift out of the measurement window, thus re-emphasizing the necessity to characterize all defect sub-populations for more reliable prediction of BTI degradation.

The $\Delta V_{t h}$ vs. $t_{\text {relax }}$ trends calculated with these CET maps is

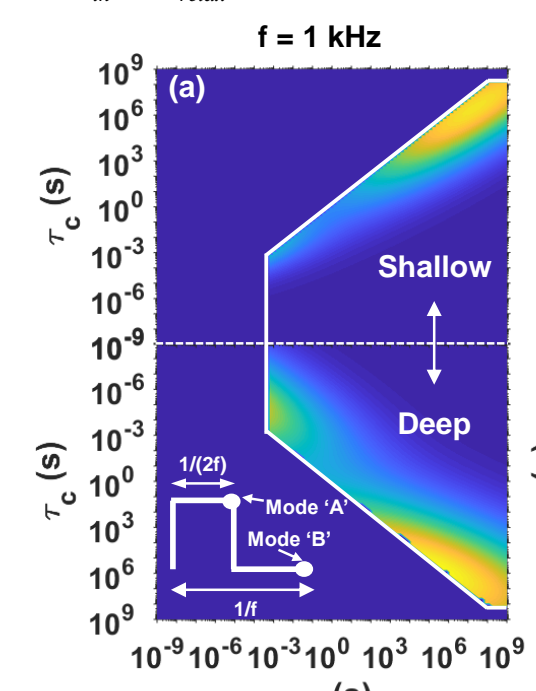

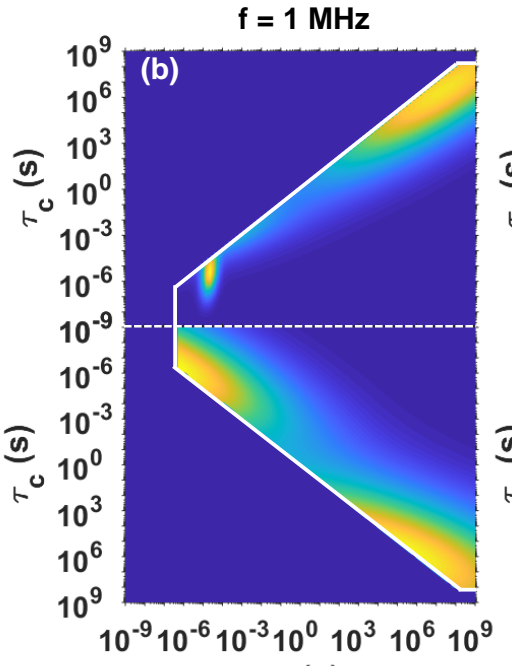

$\tau_{\mathrm{e}}(\mathbf{s})$ shown to match the experimental data comprehensively for all the BTI data.

\section{B. Active defect sub-populations under AC-operation}

The calibrated CET maps can now be used for estimating the $V_{t h}$ degradation under AC/high-frequency operating conditions as it is relevant for RF applications. CET maps obtained for T $=298 \mathrm{~K}$, and mode- $\mathrm{B}$ operation [26] with duty factor of $50 \%$ (inset of Fig. 17a) and frequencies $(f)$ of $1 \mathrm{kHz}, 1 \mathrm{MHz}$ and 1 $\mathrm{GHz}$ are shown in Fig. 17a-c and Fig. 18a-c, respectively for the $\mathrm{Al}_{2} \mathrm{O}_{3}$ [24] and ASM-IL gate-stacks. The $V_{\text {th }}$ degradation results from charging of 'Fast' and 'Slow' defect populations within the bound region, while the remaining defect states are charged during half of the AC signal period, but become discharged during the second half of the signal period. Note that the end of the second half of the signal period represents the $\tau_{\mathrm{e}}(\mathbf{s})$

Fig. 17. $\mathbf{A l}_{2} \mathbf{O}_{3}$ gate-stack: The measurable fractions of the 'fast' and the 'slow' defect populations, calculated for digital mode-B AC signal with frequencies from $1 \mathrm{kHz}$ to $1 \mathrm{GHz}$ at $25^{\circ} \mathrm{C}$. NOTE: The $\tau_{\mathrm{c}}$ axis of the lower half of CET maps (for negative oxide field condition) is reversed to represent deep defect states. Color scale may be used to understand the relative height and spread of defect populations, while the contribution of individual sub-populations to the measured $\Delta V_{\text {th }}$ is summarized in Tables I \& II $\left(\Delta V_{t h, \max }\right)$.
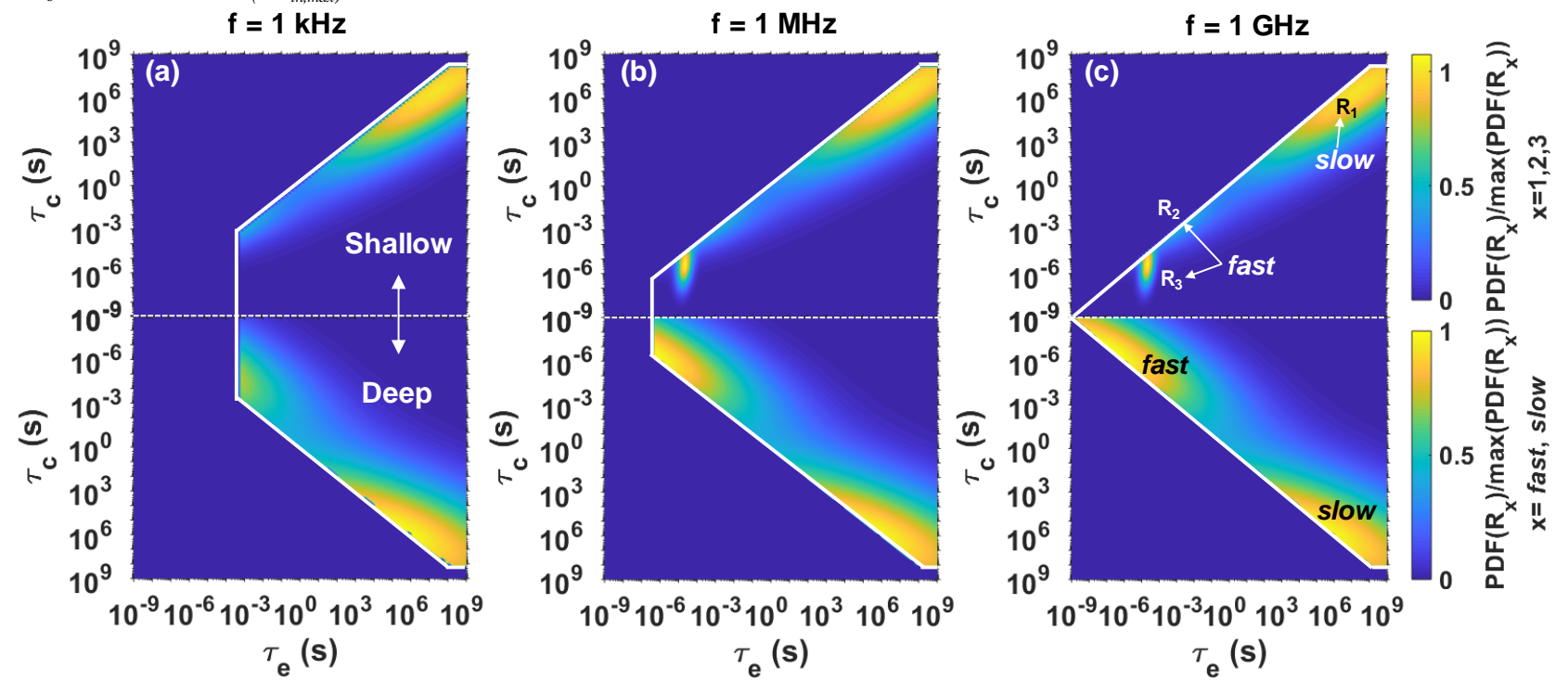

Fig. 18. ASM-IL gate-stack: The measurable fractions of the 'fast' and the 'slow' defect populations, calculated for digital mode-B AC signal with frequencies from $1 \mathrm{kHz}$ to $1 \mathrm{GHz}$ at $25^{\circ} \mathrm{C}$. NOTE: The $\tau_{\mathrm{c}}$ axis of the lower half of CET maps (for negative oxide field condition) is reversed to represent deep defect states. Color scale may be used to understand the relative height and spread of defect populations, while the contribution of individual sub-populations to the measured $\Delta V_{\text {th }}$ is summarized in Tables I \& II $\left(\Delta V_{t h, \max }\right)$. 
instant where the transistor current drive-and therefore its aging due to BTI-induced $V_{\text {th }}$ shift-is most important to drive up the output capacitance quickly. It can be noted that the ' $F a s t$ ' defect populations do not contribute to $V_{t h}$ degradation at $f=1 \mathrm{kHz}$ for both the $\mathrm{Al}_{2} \mathrm{O}_{3}$ [24] and ASM-IL gate-stacks. However, as the signal frequency is increased to $1 \mathrm{MHz}$ and eventually to 1 $\mathrm{GHz}$, significant contribution from the 'Fast' defect states can be observed.

\section{Predicting the $V_{\text {th }}$ degradation at End-of-life (10 years)}

The results of CET map model are seen to match reasonably well with the experimental data. The crucial feature in Fig. 12, i.e., significant $\Delta V_{\text {th }}$ recovery at $t_{\text {relax }} \approx 100$ s for $\mathrm{Al}_{2} \mathrm{O}_{3}$ gate-stack and at $t_{\text {relax }} \approx 50 \mathrm{~ms}$ for ASM-IL gate-stack, is adequately reproduced by CET map model, albeit the slower $\Delta V_{\text {th }}$ recovery for $t_{r e l}>1 \mathrm{~s}$ is not perfectly captured in Fig. 12b. We understand that a skewed bivariate Gaussian distribution, or a distribution with a non-Gaussian shape might be required to reproduce the entire trend accurately for the ASM-IL gate-stack.

Fig. 19 is a comparison of the $\Delta V_{t h}$ calculated for stress time up to $\sim 10$ years under DC-BTI stress conditions. Note that the $\Delta V_{t h}$ projected under DC-PBTI stress is the result of re-scaling the $\Delta V_{t h}$ vs. $t_{\text {stress }}$ at $V_{o v, \text { stress }}=1 \mathrm{~V}$ to $V_{o v}=0.5 \mathrm{~V}$ using $\gamma_{\mathrm{Al} 2 \mathrm{O} 3}=$ 1.31 for $\mathrm{Al}_{2} \mathrm{O}_{3}$ gate-stack and $\gamma_{\mathrm{ASM}-\mathrm{IL}}=3.12$ for ASM-IL gatestack (Section III). Similarly, the $\Delta V_{t h}$ projected under DCNBTI stress is the result of re-scaling the $\Delta V_{t h}$ vs. $t_{s t r e s s}$ at $V_{o v, s t r e s s}$ $=-0.8 \mathrm{~V}$ to $V_{o v}=-0.25 \mathrm{~V}$ using $\gamma_{\mathrm{Al} 2 \mathrm{O} 3}=1.66$ for $\mathrm{Al}_{2} \mathrm{O}_{3}$ gate-stack and $\gamma_{\mathrm{ASM}-\mathrm{IL}}=2.92$ for ASM-IL gate-stack. In comparison to $\mathrm{Al}_{2} \mathrm{O}_{3}$ based gate-stack, the ASM-IL based gate-stack undergoes $\sim 4 \mathrm{x}$ lower degradation under positive BTI stress
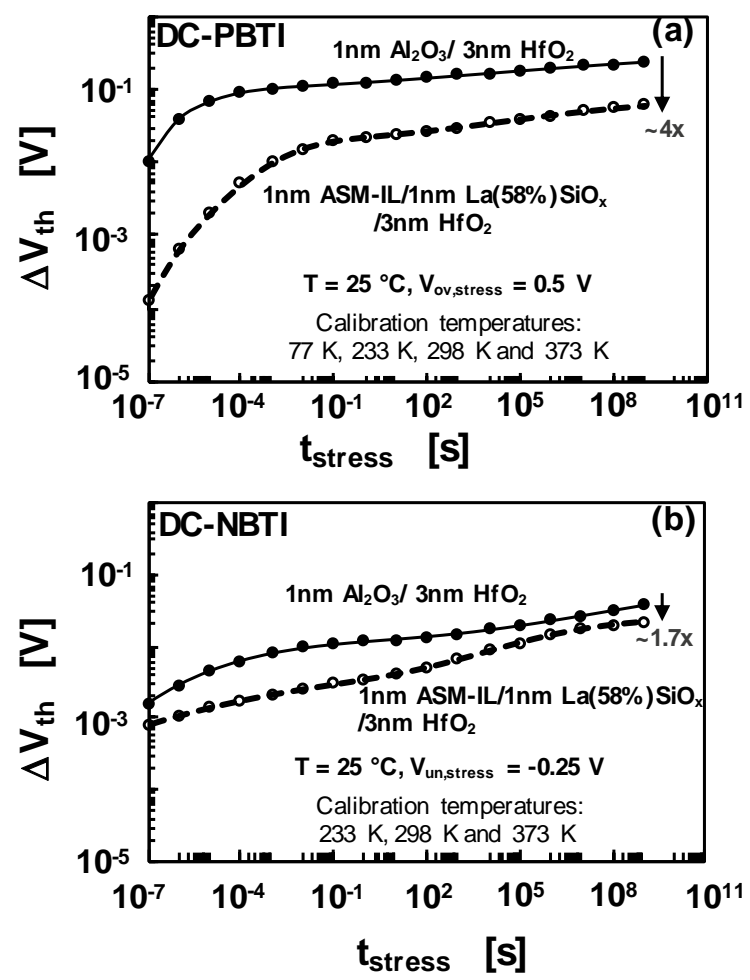

Fig. 19. The $V_{t h}$ degradation predicted for the $\mathrm{Al}_{2} \mathrm{O}_{3}$ and the ASM-IL gatestacks with (a) $V_{o v, \text { stress }}=0.5 \mathrm{~V}$ and (b) $V_{\text {un,stress }}=-0.25 \mathrm{~V}$ (obtained by scaling results obtained for $V_{o v, s t r e s s}=1 \mathrm{~V}$ and $V_{\text {un,stress }}=-0.8 \mathrm{~V}$, using $\gamma_{\mathrm{Al} 2 \mathrm{O} 3}$ and $\gamma_{\mathrm{ASM}-\mathrm{IL}}$ under DC-PBTI stress and DC-NBTI stress) at $\mathrm{T}=25^{\circ} \mathrm{C}$.
(Fig. 19a), while it is $\sim 1.7 \mathrm{x}$ lower under negative BTI stress (Fig. 19b), after $\sim 10$ years of BTI stress.

The $\Delta V_{t h}$ degradation for the two gate-stacks under ACPBTI stress and AC-NBTI stress conditions is illustrated in Fig. 20a and Fig. 20b, respectively. The ASM-IL gate-stack is again demonstrated to be more reliable $\left(\sim 5.6 \mathrm{x}\right.$ lower $\Delta V_{\text {th }}$ after 10 years) than the $\mathrm{Al}_{2} \mathrm{O}_{3}$-based gate-stack under AC-PBTI stress. In addition, the frequency dependent $\Delta V_{t h, 10 y r s}$ for ASM-IL gatestack increases by only $9 \%$ between $1 \mathrm{kHz}$ and $1 \mathrm{GHz}$, while it increases by $\sim 38 \%$ for $\mathrm{Al}_{2} \mathrm{O}_{3}$ gate-stack. This is a result of the lower density of defects accessible at shallow capture energy levels and, owing to the low charging defect density at low oxide electric field: related to the strong BTI voltage acceleration factor for ASM-IL based gate-stack.

On the other hand, the closer proximity of 'Slow' deep defect population to Fermi level (or, its lower $\left\langle E_{A c}\right\rangle$ and $\left\langle E_{A e}\right\rangle$ ) results in a substantial increase in OFF-state degradation beyond $\sim 1 \mathrm{ks}$ of stress (Fig. 20b). This result is particularly interesting as the standard benchmarking for BTI reliability, such as the effective defect density $\left(\Delta N_{\text {eff }}\right)$, estimation of $\max -V_{O V, 10 y r s}$ and max$V_{U N, 10 y r s}$ are usually performed for $\sim 1 \mathrm{ks}$. The larger distributions for 'Fast' deep defect states and the closer proximity to $E_{F}$ of 'Slow' deep defect population may adversely impact the reliability advantage gained by adding ASM-IL in the gate-stack, especially for long stress duration and at higher frequencies. Nonetheless, the total degradation at the end of 10 years of AC-BTI stress is lower $(\sim 1.65 \mathrm{x})$ for ASM-IL gatestack as compared to the $\mathrm{Al}_{2} \mathrm{O}_{3}$ gate-stack, under OFF-state stress.
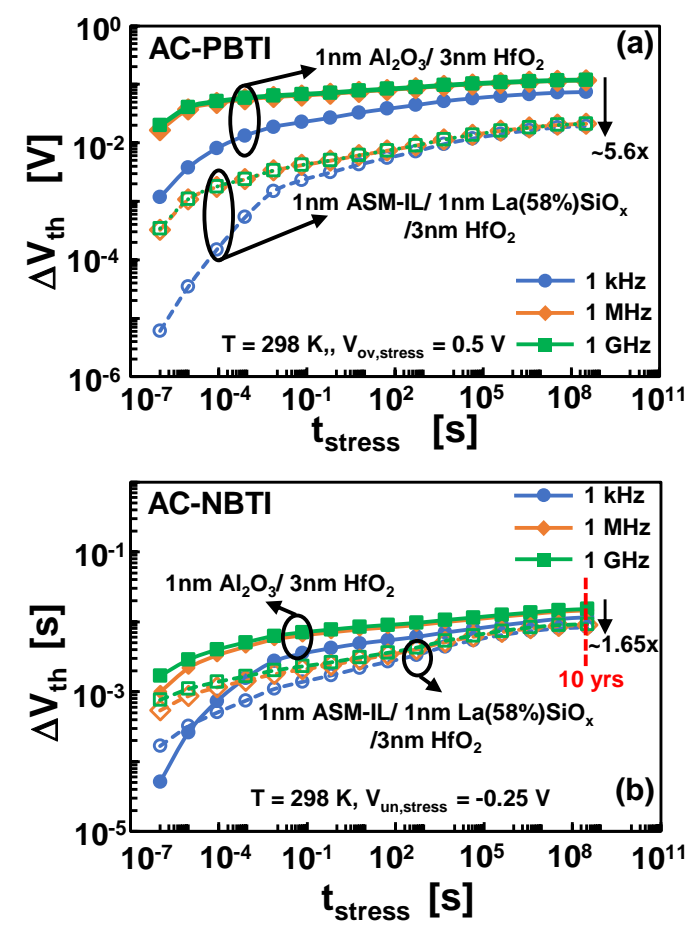

Fig. 20. Comparison of total $\Delta V_{t h}$ with increasing $t_{\text {stress }}$ at $f_{\text {signal }}=1 \mathrm{kHz}, 1 \mathrm{MHz}$ and $1 \mathrm{GHz}$ for the $\mathrm{Al}_{2} \mathrm{O}_{3}$ and ASM-IL based gate-stacks under (a) AC-PBTI stress and (b) AC-NBTI stress. Enhanced degradation is observed for longer NBTI stress times $\left(t_{\text {stress }}>\sim 1 \mathrm{ks}\right)$ for ASM-IL based gate-stack, implying that the closer proximity of 'Slow' deep defect population to $E_{F}$ as compared to its counterpart in $\mathrm{Al}_{2} \mathrm{O}_{3}$ gate-stack has considerable impact on OFF-state reliability. 


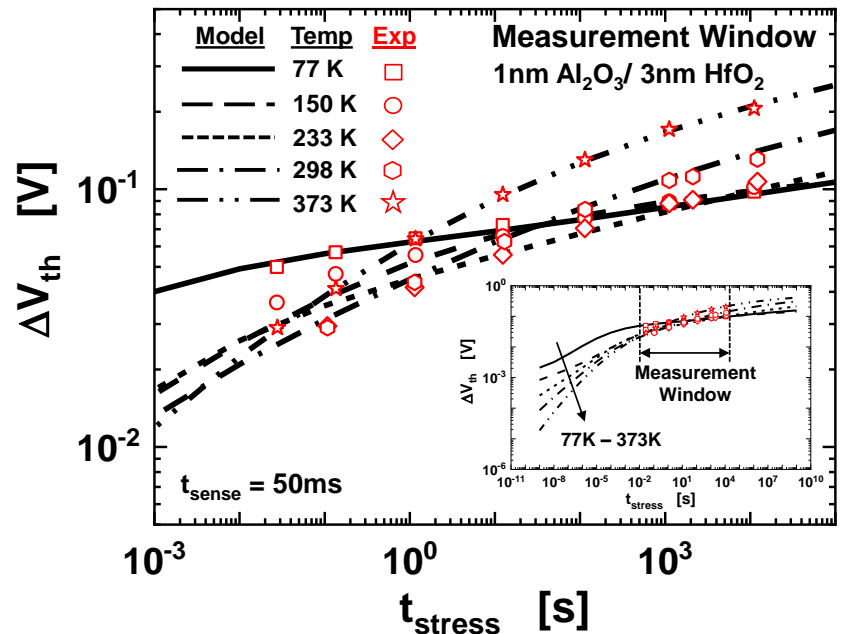

Fig. 21. The $V_{\text {th }}$ degradation of the $\mathrm{Al}_{2} \mathrm{O}_{3}$ gate-stack under DC-PBTI stress with $V_{o v, s t r e s s}=1 \mathrm{~V}$ at $\mathrm{T}=25^{\circ} \mathrm{C}$ (symbols), The predicted $V_{t h}$ degradation (lines) from the calibrated CET map for $\mathrm{Al}_{2} \mathrm{O}_{3}$ shows that temperature has astrong impact on the stress time kinetics, and results in a relatively higher $\Delta V_{t h}$ at short stress times, (Inset) The stress time is seen to significantly affect the measured temperature dependence of $\Delta V_{t h}$ in extrapolated time window (from CET maps), thus demonstrating the importance of CET map methodology.

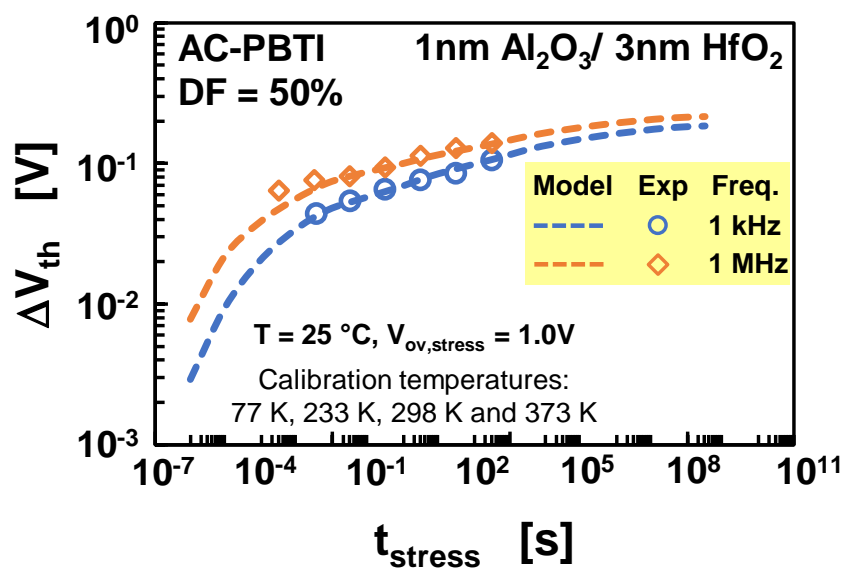

Fig. 22. The $V_{t h}$ degradation of the $\mathrm{Al}_{2} \mathrm{O}_{3}$ gate-stack was measured for ACPBTI stress with $V_{\text {ov,stress }}=1 \mathrm{~V}$ at $1 \mathrm{kHz}$ and $1 \mathrm{MHz}$ (symbols), duty factor (DF) of $50 \%$ and at $\mathrm{T}=25{ }^{\circ} \mathrm{C}$. The predicted $V_{t h}$ degradation from the calibrated CET map for $\mathrm{Al}_{2} \mathrm{O}_{3}$ matches excellently with the experimental data, thus validating the CET map model.

The DC-PBTI stress time kinetics for the entire temperature range (from $77 \mathrm{~K}$ to $373 \mathrm{~K}$ ) is compared to the experimental data in Fig. 21. It is evident that the calibrated activation energies and the $\Delta V_{\text {th }}$ vs. $t_{\text {stress }}$ calculated from the resulting CET maps are well-matched to the experimental data. An important learning from Fig. 21 is that the temperature is seen to have a significant impact on the measured $\Delta V_{\text {th }}$ for short and long stress times. An apparent opposite-Arrhenius temperature dependence of $\Delta V_{t h}$ is observed (Fig. 21 inset) for short stress times $\left(t_{\text {stress }}<\sim 1 \mathrm{~s}\right)$ and the typical Arrhenius temperature dependence of $\Delta V_{\text {th }}$ is observed for longer stress times $\left(t_{\text {stress }}\right\rangle$ $\sim 1 \mathrm{~s})$ [16].

The AC-PBTI degradation of the $\mathrm{Al}_{2} \mathrm{O}_{3}$ gate-stack was measured for $V_{o v, s t r e s s}=1.0 \mathrm{~V}\left(\mathrm{~T}=25^{\circ} \mathrm{C}\right)$, at frequencies of $1 \mathrm{kHz}$ and $1 \mathrm{MHz}$ using the Agilent B1530 WGFMU module. The minimum $t_{\text {stress }}=\sim 40 \mathrm{~ms}$ (@1kHz) and $\sim 300 \mu \mathrm{s}$ (@1MHz), and the $t_{\text {sense }}=10 \mu \mathrm{s}$ was used $\left(>1000 \mathrm{x}\right.$ shorter $t_{\text {sense }}$, as compared to $50 \mathrm{~ms}$ that was used to obtain the experimental data for CET map calibration). It is evident that the total $\Delta V_{t h}$ predicted from the CET map model, calibrated with only the DC-BTI experimental data, matches excellently in the measurement window at both the frequencies (Fig. 22).

Henceforth, the following considerations are of utmost importance for BTI benchmarking of III-V devices:

a) both shallow and deep defect distributions must be characterized to obtain the 'Total Operating Voltage Range' [15],

b) low temperature measurements are crucial to reveal the 'Fast' defect populations, as they affect the AC/highfrequency operation significantly, and

c) accounting for the time- and frequency-dependent $V_{t h}$ degradation from the CET maps is essential while designing BTI stress experiments for III-V MOS devices.

\section{RELIABILITY BENCHMARKING}

An overview of the improved reliability of the InGaAs devices with ASM-IL gate-stack is provided in the form of the most relevant benchmarking parameters typically used to assess the BTI reliability of gate-stacks.

The effective charging defect density $\left(\Delta N_{\text {eff }}\right)$ represents the active defect density that contributes to the $V_{t h}$ degradation over the operational lifetime of the device. Based on the failure criteria defined in Section III (which is similar to that for the advanced Low-Power Si nMOS devices), the typical PBTI reliability specification of $\Delta N_{\text {eff }}<3 \times 10^{10} \mathrm{~cm}^{-2}$ at an on-state operating oxide field $\left(E_{o x, O N}\right)$ of $3.5 \mathrm{MV} / \mathrm{cm}$ is comfortably achieved by the ASM-IL gate-stack (Fig. 23). While the ASMIL for InGaAs nMOS devices does not match the excellent PBTI reliability of Si nMOS devices at $E_{o x, O N}$, it is comparable to NBTI reliability of Si pMOS devices in terms of its voltage acceleration (represented by $\gamma$ ).

While it is important to ensure that the $\Delta N_{\text {eff }}$ is wellcontrolled in order to minimize the total $V_{t h}$ degradation, it is equally important to ensure that the rate of charge trapping is minimized at operating conditions. Conversely, the maximum operating overdrive voltage to achieve a BTI reliability lifetime of 10 years (max- $V_{o v, 10 y r s}$ ) can be estimated by monitoring the

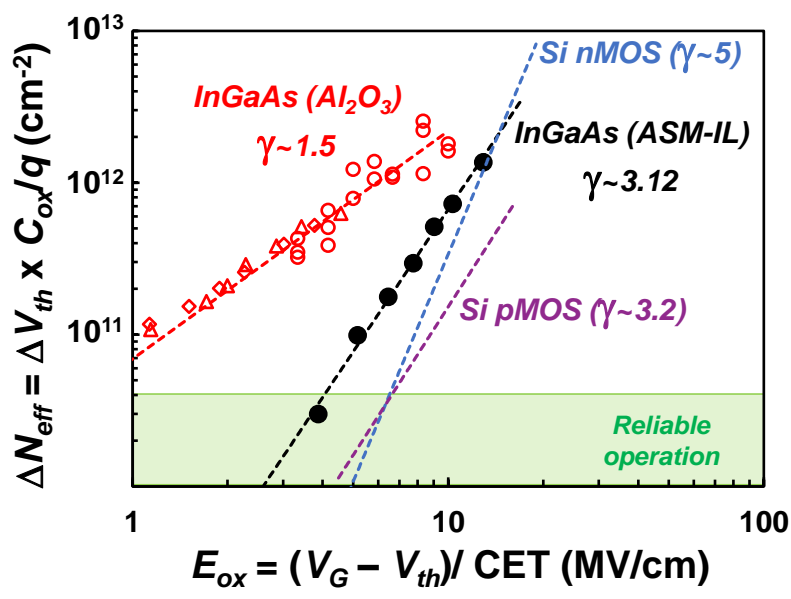

Fig. 23. The effective charging defect density $\left(\Delta N_{e f f}\right)$ of the two gate-stacks studied in this work $\left(\mathrm{Al}_{2} \mathrm{O}_{3}\right.$ and ASM-IL) is benchmarked for increasing oxide field $\left(E_{o x}\right)$ against the advanced Si nMOS/pMOS devices. The ASM-IL gatestack is seen to meet the requirements for the 'Reliable operation' regime. 


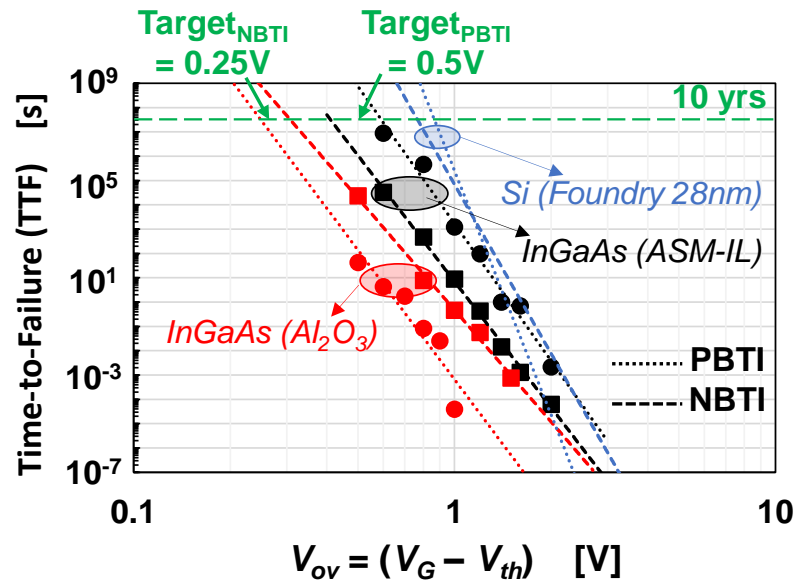

Fig. 24. The time-to-failure (TTF) based on the criteria defined in section III for the two gate-stacks studied in this work $\left(\mathrm{Al}_{2} \mathrm{O}_{3}\right.$ and ASM-IL) is benchmarked for increasing gate-overdrive bias $\left(V_{o v}\right)$ against the advanced $\mathrm{Si}$ nMOS and pMOS devices. The ASM-IL gate-stack is seen to achieve a maximum operating $V_{o v}$ of higher than $0.5 \mathrm{~V}$ for 10 years of 'Reliable operation' and is comparable with advanced $\mathrm{Si}$ nMOS/pMOS devices, while the $\mathrm{Al}_{2} \mathrm{O}_{3}$ gate-stack only achieves $\sim 0.2 \mathrm{~V}$ to $0.25 \mathrm{~V}$ for the same failure criteria.

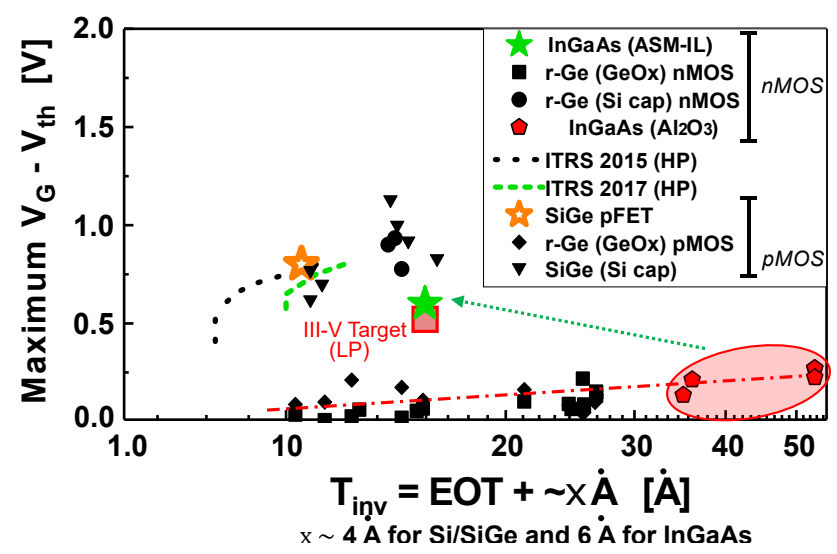

Fig. 25. The maximum $V_{o v}$ (based on the criteria defined in section III) relative to the corresponding gate-stack inversion thickness $\left(T_{i n v}\right)$ for the two gatestacks studied in this work $\left(\mathrm{Al}_{2} \mathrm{O}_{3}\right.$ and ASM-IL) is benchmarked various $\mathrm{Si}$ and Ge technologies. The ASM-IL gate-stack is seen to achieve a maximum operating $V_{o v}$ of higher than the target for 10 years of 'Reliable operation' $(0.5 \mathrm{~V})$ at the target $T_{i n v}=1.5 \mathrm{~nm}$, while the $\mathrm{Al}_{2} \mathrm{O}_{3}$ gate-stack falls short for the same failure criteria [27].

time-to-failure (TTF) (based on the failure criteria defined in Section III) at different operating overdrive gate-bias $\left(V_{o v}=V_{G}\right.$ $\left.-V_{t h}\right)$. The $\max -V_{o v, 10 y r s}$ is consequently obtained with a powerlaw extrapolation as shown in Fig. 24. It is evident that ASM-

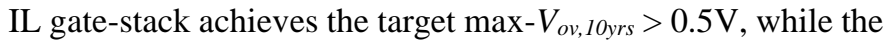
$\mathrm{Al}_{2} \mathrm{O}_{3}$ is benchmarked at a max- $V_{o v, 10 y r s} \approx 0.2 \mathrm{~V}$ (under PBTI stress).

Finally, the max- $V_{o v, 10 y r s}$ benchmark with respect to the corresponding gate-stack inversion thickness $\left(T_{i n v}\right)$ is compared for different semiconductor technologies [27] (Fig. 25). This demonstrates that achieving the $\max -V_{o v, 10 y r s}>0.5 \mathrm{~V}$ in conjunction with the target $T_{i n v}$ of $\sim 1.5 \mathrm{~nm}$ for gate-stacks of InGaAs devices is crucial for the enablement of future III-V channel-based logic technologies. Similar benchmarks may also be established for III-V channel-based RF/5G technologies.

\section{CONCLUSION}

This work presented a comprehensive reliability assessment methodology for gate-stacks of III-V channel devices. The complete CET map analysis was applied to a common gatestack comprising $1 \mathrm{~nm} \mathrm{Al}_{2} \mathrm{O}_{3} / 3 \mathrm{~nm} \mathrm{HfO}_{2}$ and an advanced gatestack comprising $1 \mathrm{~nm}$ ASM-IL/1nm La $\mathrm{La}_{58 \%} \mathrm{SiO}_{\mathrm{x}} / 3 \mathrm{~nm} \mathrm{HfO}_{2}$ gate-stack. The enhanced BTI reliability of the ASM-IL gatestack under DC and AC operating conditions was shown to be the result of lower density of defect states accessible at operating oxide field. The $V_{t h}$ degradation under OFF-state stress (negative $E_{o x}$ ) of ASM-IL based gate-stack for longer stress times $\left(t_{\text {stress }}>10^{5} \mathrm{~s}\right)$ in the AC operating conditions was additionally shown to be crucial for assessing end-of-life degradation, due to the contribution from the larger high-energy deep defect sub-populations.

Hence, it is concluded that the InGaAs devices with ASM-IL based gate-stack satisfy both the DC- and AC-BTI reliability targets for $\mathrm{ON}$ - and OFF-state operation. It is also imperative that careful assessment of AC-BTI reliability is essential for applications requiring an AC signal workload, such as future III-V (GaAs) channel devices for RF applications.

\section{REFERENCES}

[1] J. Franco, A. Alian, B. Kaczer, D. Lin, T. Ivanov, A. Pourghaderi, K. Martens, Y. Mols, D. Zhou, N. Waldron, S. Sioncke, T. Kauerauf, N. Collaert, A. Thean, M. Heyns, and G. Groeseneken, "Suitability of highk gate oxides for III-V devices: A PBTI study in In0.53Ga0.47As devices with A12O3," in 2014 IEEE International Reliability Physics Symposium, June 2014, pp. 6A.2.1-6A.2.6. DOI:10.1109/IRPS.2014.6861098

[2] J. Franco, B. Kaczer, J. Roussel, M. Cho, T. Grasser, J. Mitard, H. Arimura, L. Witters, D. Cott, N. Waldron, D. Zhou, A. Vais, D. Lin, A. Alian, M. A. Pourghaderi, K. Martens, S. Sioncke, N. Collaert, A. Thean, M. Heyns, and G. Groeseneken, "BTI reliability of high-mobility channel devices: SiGe, Ge and InGaAs," in 2014 IEEE International Integrated Reliability Workshop Final Report (IIRW), Oct 2014, pp. 5357. DOI:10.1109/IIRW.2014.7049510

[3] A. Vais, A. Alian, L. Nyns, J. Franco, S. Sioncke, V. Putcha, H. Yu, Y. Mols, R. Rooyackers, D. Lin, J. W. Maes, Q. Xie, M. Givens, F. Tang, X. Jiang, A. Mocuta, N. Collaert, K. D. Meyer, and A. Thean, "Record mobility ( $\mu$ eff_3100 $\mathrm{cm} 2 / \mathrm{V}-\mathrm{s}$ ) and reliability performance (Vov_0.5 V for $10 \mathrm{yr}$ operation) of In0.53Ga0.47As MOS devices using improved surface preparation and a novel interfacial layer," in 2016 IEEE Symposium on VLSI Technology, June 2016, pp. 1-2. DOI: 10.1109/VLSIT.2016.7573410

[4] G. Roll, J. Mo, E. Lind, S. Johansson, and L.-E. Wernersson, "Defect evaluation in InGaAs field effect transistors with $\mathrm{HfO} 2$ or $\mathrm{Al} 2 \mathrm{O} 3$ dielectric," Applied Physics Letters, vol. 106, no. 20, p. 203503, 2015. DOI:10.1063/1.4921483

[5] M. Heyns, A. Alian, G. Brammertz, M. Caymax, Y. C. Chang, L. K. Chu, B. D. Jaeger, G. Eneman, F. Gencarelli, G. Groeseneken, G. Hellings, A. Hikavyy, T. Y. Hoffmann, M. Houssa, C. Huyghebaert, D. Leonelli, D. Lin, R. Loo, W. Magnus, C. Merckling, M. Meuris, J. Mitard, L. Nyns, T. Orzali, R. Rooyackers, S. Sioncke, B. Soree, X. Sun, A. Vandooren, A. S. Verhulst, B. Vincent, N. Waldron, G. Wang, W. E. Wang, and L. Witters, "Advancing CMOS beyond the Si roadmap with Ge and III/V devices," in 2011 International Electron Devices Meeting, Dec 2011, pp. 13.1.1-13.1.4. DOI:10.1109/IEDM.2011.6131543

[6] S. Oktyabrsky and D. Y. Peide, Fundamentals of III-V semiconductor MOSFETs. Springer, 2010

[7] M. Heyns, A. Alian, G. Brammertz, M. Caymax, G. Eneman, J. Franco, F. Gencarelli, G. Groeseneken, G. Hellings, A. Hikavyy, M. Houssa, B. Kaczer, D. Lin, R. Loo, C. Merckling, M. Meuris, J. Mitard, L. Nyns, S. Sioncke, W. Vandervorst, B. Vincent, N. Waldron, and L. Witters, "Challenges for introducing $\mathrm{Ge}$ and III/V devices into CMOS technologies," in 2012 IEEE International Reliability Physics 
Symposium (IRPS), April 2012, pp. 5D.1.1-5D.1.10. DOI:10.1109/IRPS.2012.6241852

[8] C. A. Lin, H. C. Chiu, T. H. Chiang, T. D. Lin, Y. H. Chang, W. H. Chang, Y. C. Chang, W.-E. Wang, J. Dekoster, T. Y. Hoffmann, M. Hong, and J. Kwo, "Attainment of low interfacial trap density absent of a large midgap peak in In0.2Ga0.8As by $\mathrm{Ga} 2 \mathrm{O} 3(\mathrm{Gd} 2 \mathrm{O} 3)$ passivation," Applied Physics Letters, vol. 98, no. 6, p. 062108, 2011. DOI: $10.1063 / 1.3554375$

[9] L. K. Chu, C. Merckling, A. Alian, J. Dekoster, J. Kwo, M. Hong, M. Caymax, and M. Heyns, "Low interfacial trap density and sub-nm equivalent oxide thickness in $\mathrm{In} 0.53 \mathrm{Ga} 0.47 \mathrm{As}$ (001) metaloxidesemiconductor devices using molecular beam deposited HfO2/Al2O3 as gate dielectrics," Applied Physics Letters, vol. 99, no. 4, p. 042908, 2011. DOI:10.1063/1.3617436

[10] J. Huang, N. Goel, H. Zhao, C. Y. Kang, K. S. Min, G. Bersuker, S. Oktyabrsky, C. K. Gaspe, M. B. Santos, P. Majhi, P. D. Kirsch, H. H. Tseng, J. C. Lee, and R. Jammy, "InGaAs MOSFET performance and reliability improvement by simultaneous reduction of oxide and interface charge in ALD (La)AlOx/ZrO2 gate stack," in 2009 IEEE International Electron Devices Meeting (IEDM), Dec 2009, pp. 1-4. DOI:10.1109/IEDM.2009.5424357

[11] G. Roll, E. Lind, M. Egard, S. Johansson, L. Ohlsson, and L. E. Wernersson, "RF and DC Analysis of Stressed InGaAs MOSFETs," IEEE Electron Device Letters, vol. 35, no. 2, pp. 181-183, Feb 2014. DOI: 10.1109/LED.2013.2295526

[12] N. Agrawal, A. V. Thathachary, S. Mahapatra, and S. Datta, "Impact of Varying Indium(x) Concentration and Quantum Confinement on PBTI Reliability in InxGa1-xAs FinFET," IEEE Electron Device Letters, vol. 36, no. 2, pp. 120-122, Feb 2015. DOI:10.1109/LED.2014.2385055

[13] C. L. Hinkle, A. M. Sonnet, E. M. Vogel, S. McDonnell, G. J. Hughes, M. Milojevic, B. Lee, F. S. Aguirre-Tostado, K. J. Choi, H. C. Kim, J. Kim, and R. M. Wallace, "GaAs interfacial self-cleaning by atomic layer deposition," Applied Physics Letters, vol. 92, no. 7, p. 071901, 2008. DOI:10.1063/1.2883956

[14] J. Franco, A. Alian, B. Kaczer, D. Lin, T. Ivanov, A. Pourghaderi, K. Martens, Y. Mols, D. Zhou, N. Waldron, S. Sioncke, T. Kauerauf, N. Collaert, A. Thean, M. Heyns, and G. Groeseneken, "Suitability of highk gate oxides for III-V devices: A PBTI study in In $0.53 \mathrm{Ga} 0.47$ As devices with Al2O3," in 2014 IEEE International Reliability Physics Symposium, June 2014, pp. 6A.2.1-6A.2.6. DOI:10.1109/IRPS.2014.6861098

[15] V. Putcha, J. Franco, A.Vais, S. Sioncke, B. Kaczer, Q. Xie, P. Calka, F. Tang, X. Jiang, M. Givens, et al., "BTI reliability of InGaAs nMOS gatestack: On the impact of shallow and deep defect bands on the operating voltage range of III-V technology", in 2017 IEEE International Reliability Physics Symposium (IRPS), pp. XT-8. IEEE, 2017

[16] V. Putcha, J. Franco, A. Vais, S. Sioncke, B. Kaczer, D. Linten, and G. Groeseneken, "On the Apparent Non-Arrhenius Temperature Dependence of Charge Trapping in IIIV/High-k MOS Stack," IEEE Transactions on Electron Devices 65, no. 9 (2018): 3689-3696

[17] A. Alian, M. A. Pourghaderi, Y. Mols, M. Cantoro, T. Ivanov, N. Collaert, and A. Thean, "Impact of the channel thickness on the performance of ultrathin InGaAs channel MOSFET devices," 2013 IEEE International Electron Devices Meeting, Washington, DC, 2013, pp. 16.6.1-16.6.4. DOI: 10.1109/IEDM.2013.6724644

[18] J. Decobert and G. Patriarche, "Transmission electron microscopy study of the $\mathrm{InP} / \mathrm{InGaAs}$ and $\mathrm{InGaAs} / \mathrm{InP}$ heterointerfaces grown by metalorganic vapor-phase epitaxy," Journal of Applied Physics, vol. 92, no. 10, pp. 5749-5755, 2002. DOI:10.1063/1.1513891

[19] Sonja Sioncke, Laura Nyns, Tsvetan Ivanov, D Lin, Jacopo Franco, Abhitosh Vais, Mahmoud Ameen, Annelies Delabie, Qi Xie, Jan Willem Maes, Fu Tang, Michael Givens, S. Van Elshocht, Frank Holsteyns, Kathy Barla, Nadine Collaert, Aaron Thean, Stefan De Gendt, and Marc Heyns, "Engineering the III-V Gate Stack Properties by Optimization of the ALD Process," Electrochemical Society Transactions 2014 64: 133144. DOI: $10.1149 / 06409.0133$ ecst

[20] B. Kaczer, T. Grasser, J. Roussel, J. Martin-Martinez, R. O’Connor, B. J. O'Sullivan, and G. Groeseneken, "Ubiquitous relaxation in BTI stressing - New evaluation and insights," in 2008 IEEE International Reliability Physics Symposium, April 2008, pp. 20-27. DOI:10.1109/RELPHY.2008.4558858

[21] A. Vais, J. Franco, H.C. Lin, N. Collaert, A. Mocuta, K. De Meyer, and A. Thean. "Impact of starting measurement voltage relative to flat-band voltage position on the capacitance-voltage hysteresis and on the defect characterization of InGaAs/high-k metal-oxide-semiconductor stacks." Applied Physics Letters 107, no. 22 (2015): 223504. DOI: $10.1063 / 1.4936991$

[22] MDLab (Modeling Dielectric Laboratory). [Online]. Available: http://www.mdlab-software.com/

[23] T. Grasser, "The capture/emission time map approach to the bias temperature instability," in Bias Temperature Instability for Devices and Circuits. New York, NY, USA: Springer, 2013, pp. 447-481, doi: 10.1007/978-1-4614-7909-3_17

[24] V. Putcha, J. Franco, A. Vais, B. Kaczer, S. Sioncke, D. Linten, G. Groeseneken, "III-V gate-stack reliability characterization : On the impact of fast and slow oxide traps on IIIV MOSFET operation, studied by Capture-Emission-Time maps", in 2018 IEEE International Reliability Physics Symposium (IRPS), pp. 5A-3. IEEE, 2018

[25] A. Vais et al., "Temperature dependence of frequency dispersion in III$\mathrm{V}$ metal-oxide-semiconductor $\mathrm{C}-\mathrm{V}$ and the capture/emission process of border traps," Appl. Phys. Lett., vol. 107, no. 5, p. 053504, 2015, doi: $10.1063 / 1.4928332$

[26] N. Goel, N. Nanaware, and Souvik Mahapatra., "Ultrafast AC-DC NBTI characterization of deep IL scaled HKMG p-MOSFETs," IEEE Electron Device Letters 34, no. 12 (2013): 1476-1478

[27] Putcha, V., "Reliability Characterization of Gate-stacks for III-V Channel MOSFETs," 2019. Url: https://limo.libis.be/primoexplore/fulldisplay?docid=LIRIAS2363730\&context=L\&vid=Lirias\&s earch_scope $=$ Lirias\&tab $=$ default_tab\&lang $=$ en_US 